\title{
A Study on the Historical Materials of the Apollo Pythios Temple in Rhodes and the Evaluation of Potential Restoration Materials
}

\author{
Maria Apostolopoulou 1,*, Vasileios Keramidas ${ }^{1,+}$, Niki Galanaki ${ }^{1,+}$, Myrto Kalofonou ${ }^{1, \dagger}$, \\ Chariklia Skoula 1, + , Maria Karoglou 1, + , Ekaterini T. Delegou 1, + , Charalampos Mouzakis ${ }^{2,+}$, \\ Asterios Bakolas 1,+ , Antonia Moropoulou 1,*, Maria Pikoula ${ }^{3,+}$, Anna Kalagri 3, + , \\ Eleni Farmakidou ${ }^{3,+}$ and Maria Michailidou ${ }^{3,+}$
}

1 School of Chemical Engineering, National Technical University of Athens, Zografou 15780, Athens, Greece; bkeramidas@hotmail.gr (V.K.); nikgal_19@hotmail.gr (N.G.); mirtanta@gmail.com (M.K.); xaraskoula@hotmail.com (C.S.); margo@central.ntua.gr (M.K.); edelegou@central.ntua.gr (E.T.D.); abakolas@mail.ntua.gr (A.B.)

2 School of Civil Engineering, National Technical University of Athens, Zografou 15780, Athens, Greece; harrismo@central.ntua.gr

3 Ephorate of Antiquities of Dodecanese, Ministry of Culture and Sports of the Hellenic Republic, Rhodes 85131, Greece; mariapikoula@yahoo.gr (M.P.); annakalagri@yahoo.gr (A.K.); efarmakidou@culture.gr (E.F.); mmichailidou@culture.gr (M.M.)

* Correspondence: mairi_apostol@hotmail.com (M.A.); amoropul@central.ntua.gr (A.M.); Tel.: +30-2107723103 (M.A.); +30-2107723276 (A.M.)

+ These authors contributed equally to this work.

Received: 20 February 2019; Accepted: 18 March 2019; Published: 22 March 2019

\begin{abstract}
The Temple of Apollo Pythios, built in the Hellenistic era (3rd-1st century BC), is located in the ancient Acropolis of Rhodes. It was excavated during the Italian occupation and reconstructed by the Italians in the period 1937-8. The method of the "scenographic" restoration was the "mixed structure" technique using a core of reinforced concrete in combination with new biocalcarenite stones and the integration of very few ancient architectural members. Its proximity to the sea and the corresponding salt decay phenomena, aggravated by the erroneous reconstruction methodology and materials, have further deteriorated its state of preservation. Today, the four columns, epistyle and entablature of the Italian interventions demand immediate restoration actions to ensure the monument's sustainability. This can only be achieved through a combined study of the performance of potential restoration materials and assessment of their compatibility with the historical materials. In the present study, the characteristics of the Temple's historical porous stones are presented along with the characteristics of five quarry stones, aiming to evaluate which quarry stone is the most appropriate for use in the upcoming restoration. Restoration mortars are designed and evaluated in respect to both the historical materials and the quarry stones, aiming to select the optimum restoration mortar, which can achieve the required level of performance and compatibility and ensure sustainability of the structure as a whole.
\end{abstract}

Keywords: Apollo Pythios; Rhodes; biocalcarenite; mortars; compatibility; performance; stones; monuments; assessment; restoration

\section{Introduction}

Ancient temples pose an important part of Greece's built cultural heritage assets. Ancient temples consist of multi-drum or monolithic columns (colonnades), connected at the top with entablature. 
The columns are composed of large blocks (drums) of stone with no connecting mortar [1]. In antiquity, different lithotypes were used for the construction of stone temples. In Athens, due to the relative proximity of the pentelic marble quarries and due to the significance of the temples in addition to the economic robustness of the region, especially in classical times, pentelic marble was the choice material, as evidenced in many such monuments (Acropolis monuments, Temple of Hephaistos in the ancient Agora, Poseidon Temple in Sounion); pentelic marble is perhaps the most famous lithotype used in ancient Greek Temples [2-4]. However, across Greece, different types of stones have been used in ancient temples, according to the proximity of quarries, geology of the region, the religious and societal importance of the Temple, the economic status of the region and the construction technology of the era. Greece is rich in stone materials, excellent for use in architecture, each area offering its own particular geological deposits. The most widely available types of stone are limestone, calcarenite and sandstone. Therefore, many important and exemplary temples were built with the use of other types of stones, locally available. The Temple of Apollo in Bassae, was built with a compact type of limestone, locally available in the Peloponnese, the Temple at Olympia was built using a local biocalcarenite, while in ancient Corinth a soft porous limestone, quarried near the city was used as structural material [5]. In Rhodes, biocalcarenites were quarried locally and used for the construction of various monumental structures throughout time.

Ancient temples today are in need of restoration, due not only to natural ageing of the materials composing them, after millennia in service, but also due to destruction, vandalism and explosions during periods of unrest or war, and dynamic stresses, as Greece is a region with frequent and strong earthquakes. The building materials of these structures are also subject to environmental factors, such as sea salt spray, in the case of monuments in close proximity to the sea, and consequent salt crystallization; pollution, in the case of monuments which are located in the city center; biodeterioration, and of course the synergistic effect of all the above. Among deterioration factors, the use of incompatible restoration materials, holds an important place, as evident in many ancient temples, where the use of incompatible materials further worsened the state of preservation, demanding the restaurio di restaurio, a supreme example of which is the archaeological site of Knossos [6,7]. This is attributed to the different properties of modern materials, such as cement, which increase rigidity of the structure, cause moisture accumulation in the more porous historical materials, thus accelerating or even triggering consequent deterioration mechanisms, deliver stresses to the weaker historical materials, thus causing damages, while incompatible restoration materials can cause chemical alterations of the historical materials or can introduce dangerous salts into the structure [8-15].

The Temple of Apollo Pythios is located at the western part of the ancient Acropolis of Rhodes. It was constructed in the Hellenistic to late Hellenistic era (3rd-1st century BC). It was of Doric order, peripteral, made of local porous stone, with six columns at the short side, 11 at the long side, orientated from east to west and of dimensions $\sim 20.05 \times 37.70 \mathrm{~m}$. Each column of the temple of Apollo was $11.0 \mathrm{~m}$ high and was composed of eleven $1.0 \mathrm{~m}$ high drums and a capital. The diameter at the base is $1.77 \mathrm{~m}$ and at the top $1.40 \mathrm{~m}[1,16]$. During the Italian occupation of the island (1912-45), the site was excavated and the temple was reconstructed by the Italians in the period 1937-8 [17]. The method of the "scenographic" restoration was the "mixed structure" technique using a core of reinforced concrete in combination with new biocalcarenite stones and the integration of very few ancient architectural members [18]; thus, the extensive reconstruction of the Temple took place using concrete and cement materials, steel elements and fragments of the original material, in accordance to the practices of the era (hereon "Italian restoration").

The Temple was severely damaged during bombings in the Second World War and from 1946 inwards the Greek Archaeological Service undertook the difficult task of conservation. In its current state, immediate measures were taken and the Temple is enclosed in scaffolding in order to prevent its collapse, while remaining parts of the Temple include the stereobate, the reconstructed elevations to the north and east and four restored columns with a fragment of the entablature and the pediment at the northeast (Figure 1a). 

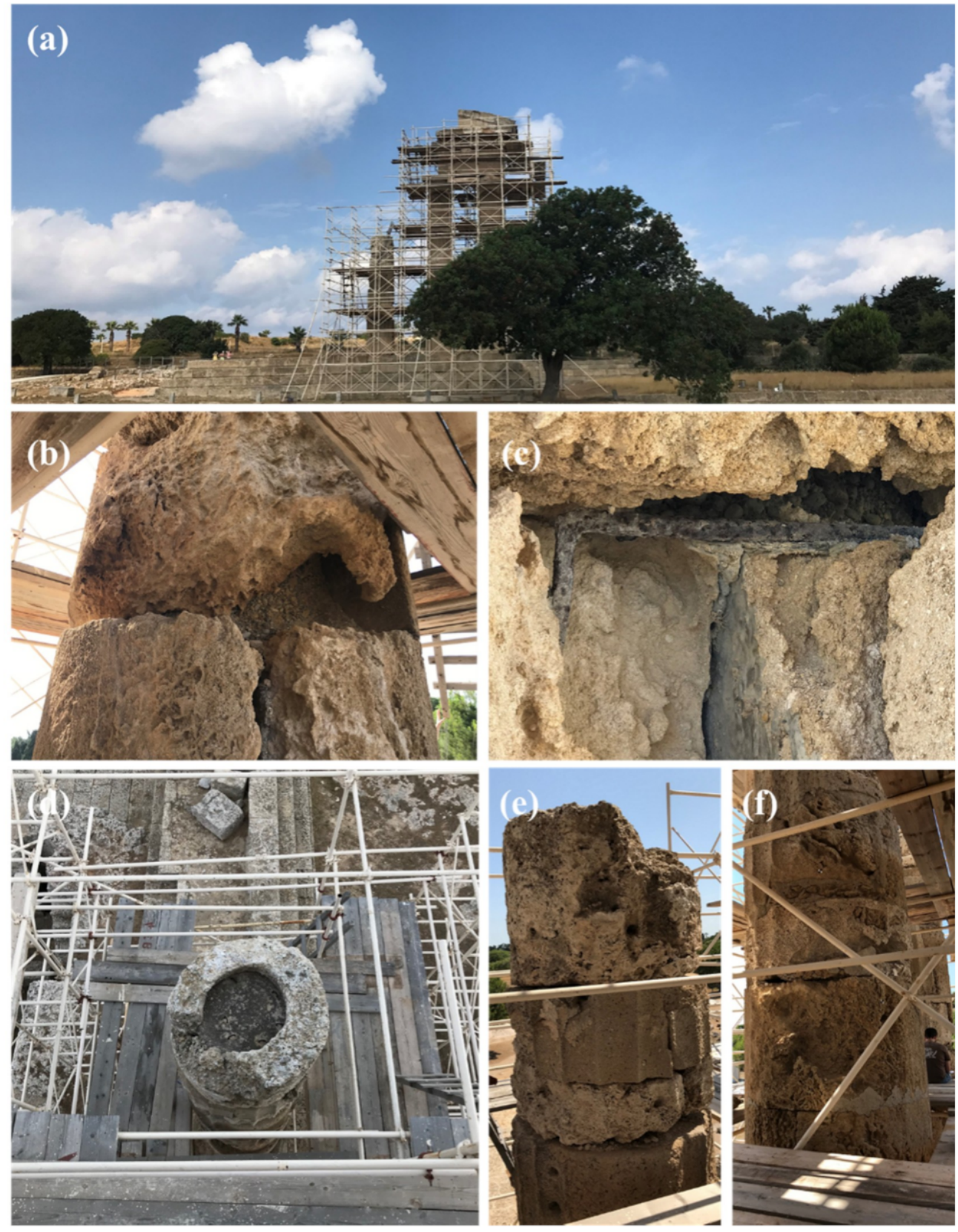

Figure 1. Temple of Apollo Pythios in Rhodes (a) Temple in its current state; (b) stone applied during the Italian restoration, in a bad state of preservation; (c) corroded metal element within column, disintegrated cement concrete and the deteriorated restoration stone applied during the Italian restoration; (d) image of free column from above, where one can notice how the interior of the column was carved out and filled with reinforced concrete during the Italian restoration; (e,f) upper and lower part of free standing column, where the manner in which the ancient, the restoration and the concrete materials have been used and bound together can be noticed.

Unfortunately, the extensive works implemented during the Italian restoration rather accelerated the deterioration of the Temple. The repair stone used was highly susceptible to deterioration from salt spray (alveolar weathering), as evidenced by its bad state of preservation, even visually observed (Figure 1b,c); the cement used to join together the ancient stone fragments, as well as the concrete poured in large areas where material was missing and in the interior of the carved out drums (Figure 1c,d), materials highly incompatible with the historical stone, created breathability issues and a highly anisotropic behavior of the structure in relation to mechanical and hygric loads, at the 
same time introducing damaging salts into the masonry $[19,20]$. The above, in combination with the corrosion and expansion of steel elements embedded within the building materials during the Italian restoration, have greatly damaged the remaining part (Figure 1c); a testimony of the reality than reinforced concrete in the Mediterranean area has a lifetime expectance of 50-100 years. The Temple of Apollo Pythios is an example of how the use of incompatible materials can endanger the sustainability of a monument and the manner in which the durability of a monument is interlinked with the materials and techniques used to restore it.

Therefore, today, the Temple is in a bad state of preservation, demanding a new major restoration project, which must apply new compatible stones and mortars, after removing all incompatible past restoration materials. In the present study, the historical materials of the Temple are analyzed, five (5) quarry stones are assessed aiming to ascertain as to their compatibility and performance, while new mortars are designed, evaluated and proposed for various applications in the framework of the upcoming restoration project.

\section{Materials and Methods}

In the present work, three samples of historical stones from the columns of the Temple were studied aiming to examine the characteristics of the historical materials; one sample of ancient stone from the second to top drum of the free standing column coded "Ancient Stone 1", one sample of ancient stone from the top drum of the same column, coded "Ancient Stone 2" (Figure 1e, the latter presenting a whiter coloration and more weathered appearance), and one sample of the restoration stone used during the Italian restoration of the early- to mid-20th century (Figure 1f) coded "Italian Restoration".

Aiming to select an appropriate restoration stone, stone specimens were examined from five different quarries; the quarries were selected after investigation of which organized quarries in the Mediterranean basin could procure blocks of the required dimensions for the restoration project. Specifically, the lithotypes examined were: (a) a biocalcarenite from a quarry in Murcia, Spain (PAR_Alb), (b) a biocalcarenite from Tochni, Cyprus (PAR_K) and (c) a litharenite from Achaia, Greece (PAR_Dask). In addition, specimens from two different locations (coded Location A and Location B) of an inactive quarry in the area of Stegna, Rhodes were examined, in order to study a locally quarried biocalcarenite as well (lithotypes PAR_Sa and PAR_Sb from Location A and B respectively). The locations of the different quarries are presented in Figure 2a, while the relative position of Rhodes and the Apollo Pythios Temple are presented in Figure $2 \mathrm{~b}-\mathrm{d}$. 

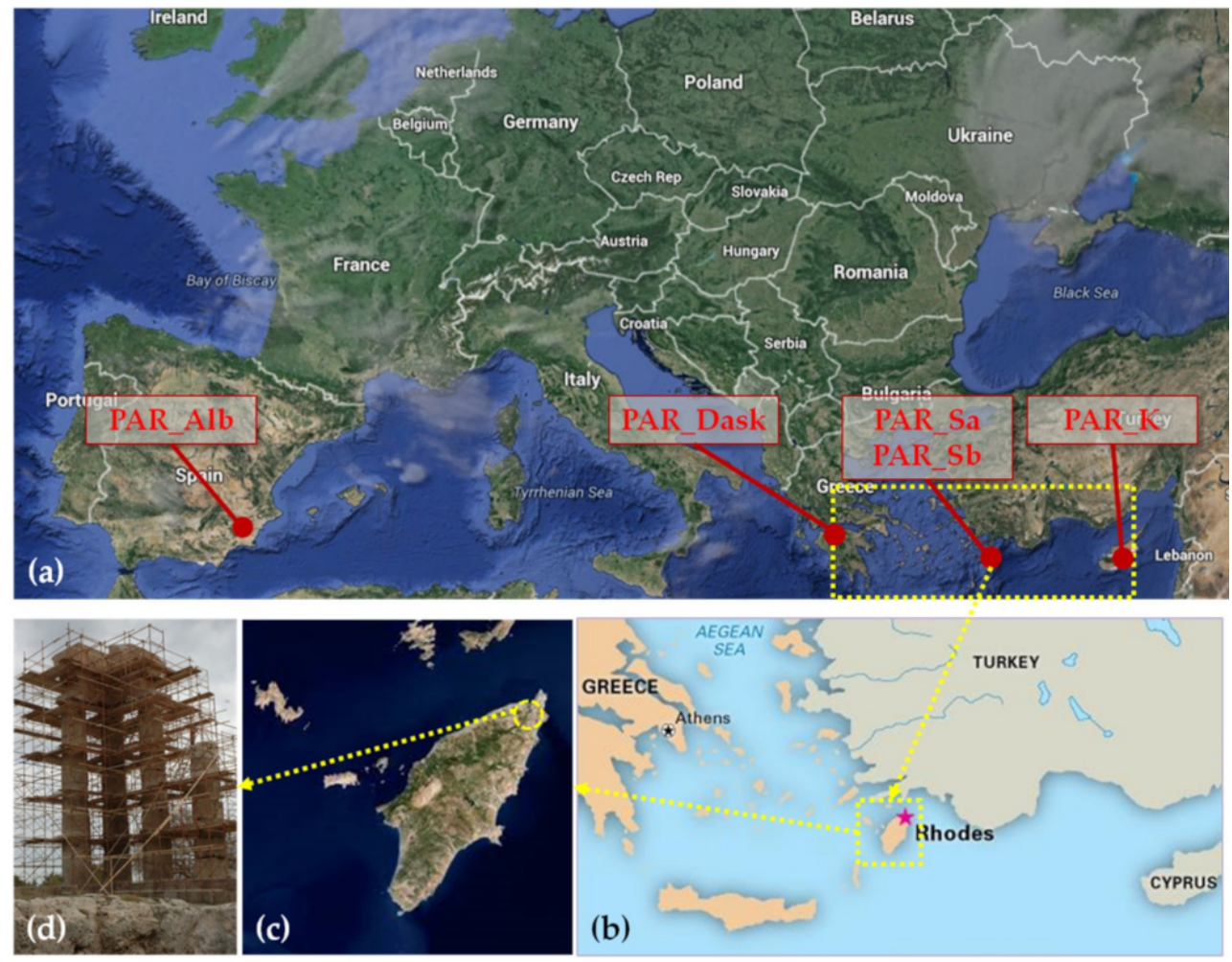

Figure 2. (a) Location of quarries from which the quarry stones examined in this study were selected; (b) Position of the island of Rhodes in the southeast Mediterranean; (c) view of the island of Rhodes and position of the Apollo Pythios Temple; (d) the Apollo Pythios Temple.

Restoration mortars were produced using CL-90 lime powder, siliceous sand (0-2 $\mathrm{mm})$ and pozzolanic additives (metakaolin, natural pozzolan) and evaluated up to 90 days of curing, while a commercial lime-metakaolin based mortar was also examined.

In the present study, petrographic examination of the historical and quarry stones was achieved using a polarized light microscope (Leica DM2500P optical microscopy mounted with a Nikon camera). Mineralogical examination of the stone samples was conducted through X-ray diffraction, using a Bruker D8 Advance, set to $\mathrm{V}=40 \mathrm{kV}, \mathrm{I}=40 \mathrm{~A}$ and $2 \theta$ from 5-60 with a 0.05 increment [21-23]. Thermal analysis and specifically thermogravimetric (TG) and differential thermal analysis (DTA) was conducted to examine the materials' composition. Thermal analysis was also conducted on the restoration mortar samples, at different curing times, in order study the evolution of hardening. For this purpose, a Regulus 2500 simultaneous thermal analysis system manufactured by Netzsch was utilized, applying a temperature range of $30-1000{ }^{\circ} \mathrm{C}$ with a temperature increase rate of $10^{\circ} \mathrm{C}$ [22]. Mercury Intrusion Porosimetry (MIP) was employed to study microstructural characteristics of the historical stone samples and the quarry stones, using a Pascal 400 Thermo-Electronics-Corporation [21,24]. Water capillary rise tests were conducted on stone specimens (dimensions $5 \mathrm{~cm} \times 5 \mathrm{~cm} \times 5 \mathrm{~cm}$ ) acquired from the different quarries to examine hygric properties, in accordance to EN 15801 (2010), while the same procedure was also applied on cubic specimens of the same dimensions to study the hygric properties of the restoration mortars [25]. Total immersion tests were also conducted.

Compressive strength measurements were conducted on cubic specimens (dimensions: $5 \mathrm{~cm} \times 5$ $\mathrm{cm} \times 5 \mathrm{~cm}$ ) of the quarry stones in accordance to EN 1926 [26], while ultrasound velocity measurements were conducted on both the quarry stones and the restoration mortars, using a Pundit-CNS Electronics with two different transducers, a transmitter and a receiver, that were applied at the ends of the specimens, with a source pulse frequency of $54 \mathrm{kHz}$. Flexural and compressive strength measurements were conducted on the hardened mortar specimens in accordance to EN1015-11; three specimens 
$(16 \mathrm{~cm} \times 4 \mathrm{~cm} \times 4 \mathrm{~cm}$ ) were measured for flexural and six specimens (dimensions $4 \mathrm{~cm} \times 4 \mathrm{~cm}$ $\times 4 \mathrm{~cm}$ ) were measured for compressive strength for each mortar [27]. In order to determine the color parameters of the historical materials, as well as the restoration materials, colorimetry measurements were conducted [28], using a Dr Lange colorimeter (LMG268). Specific conductivity and $\mathrm{pH}$ measurements of the mortar samples at different ages were also conducted. In order to perform the measurements, $100 \mathrm{mg}$ of pulverized samples were mixed with $100 \mathrm{~mL}$ of deionized water and left to rest for $24 \mathrm{~h}$. Fresh mortar characteristics were conducted in accordance to EN1015-3, EN1015-6, EN1015-8, thus determining consistency, bulk density and retained water, respectively [29-31].

\section{Results}

As already mentioned, the Temple of Apollo Pythios is in a bad state of preservation, now surrounded with a metal scaffolding. The Central Archaeological Council of Greece has decided that a major restoration will take place. It has been decided that the materials used in the Italian restoration will be removed: cement, reinforced concrete and the Italian Restoration stone, which has greatly deteriorated, as well as the metal elements which are corroded and further negatively affecting the structural state of the monument [19].

If the structural analysis of the monument results in the possibility of using the deteriorated stone fragments of the ancient members (i.e., what is considered as part of the original monument), the fragments will be preserved and joined together through mortar with a new stone, which must be compatible with the historical one and of sufficient mechanical strength. Where no historical stone is present, the drums will be completely substituted with the new stone. A restoration mortar will be used to join together new and historical stone fragments and, where necessary, titanium elements will be used to secure the connection (as titanium has proven to be less susceptible to corrosion than other metals). In any case, the aim of the restoration project is to maintain the form of the monument as it is today, the four columns with the epistyle and entablature, a landmark which crowns the ancient Acropolis of Rhodes. In the following sections, the results from the characterization of the historical stones of the monument are presented, along with the results from the characterization of five (5) lithotypes from various quarries, which are to be evaluated in terms of compatibility and performance for use in the upcoming restoration works. In addition, the characteristics of four restoration mortars are presented and assessed.

\subsection{Characterization of Historical and Quarry Stones}

The historical stone samples, as well as the quarry stone samples, were studied through various techniques, in order to examine their characteristics and evaluate the new quarry stones in terms of compatibility with the historical ancient stone, as well as in terms of performance, aiming to achieve the optimum response of the monument under environmental loads and dynamic stresses.

\subsubsection{Petrography Examination Results}

The stone samples, both historical and quarried, were examined using a polarized light microscope (Figure 3). 

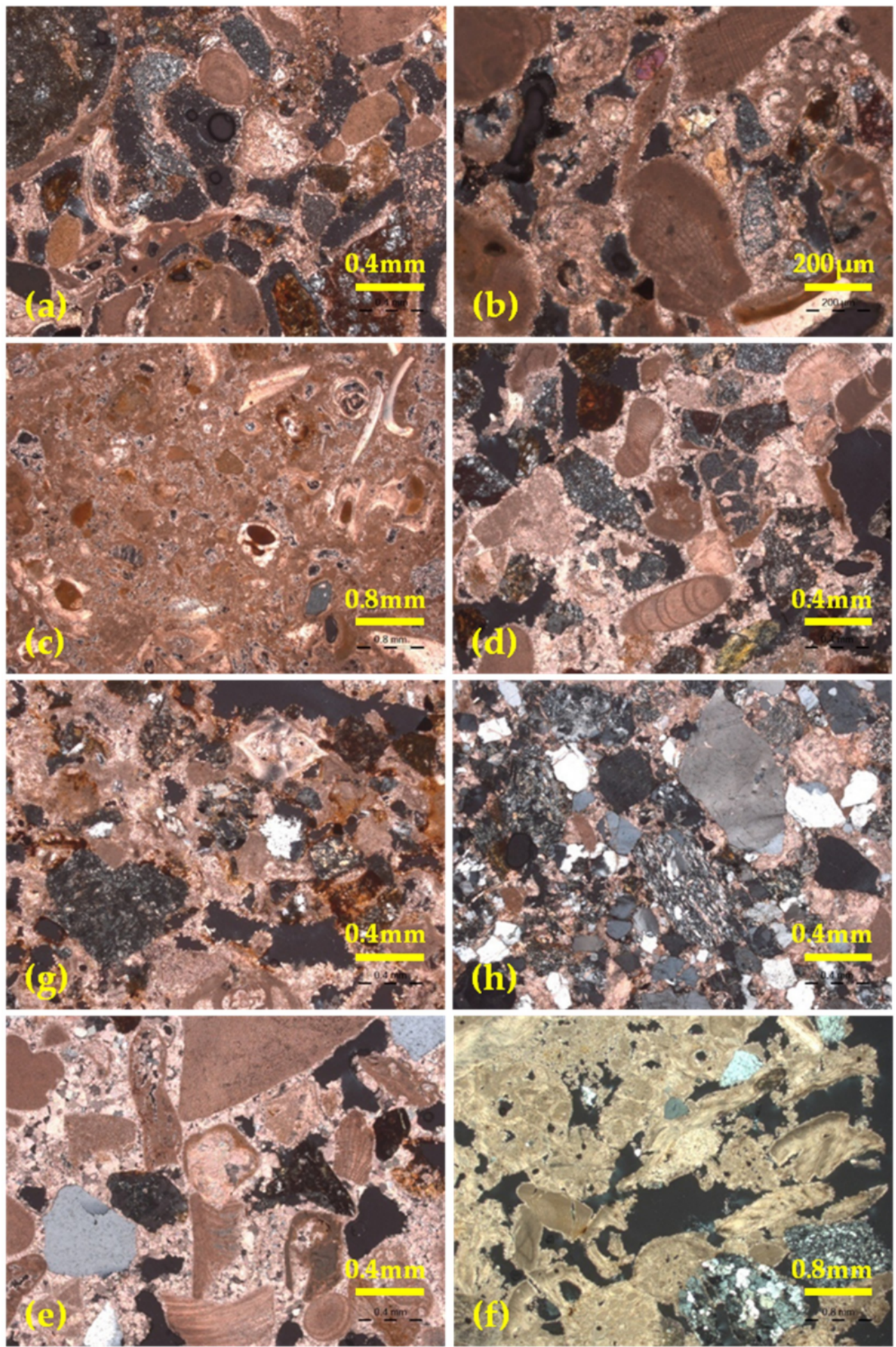

Figure 3. Polarized microscope images of (a) Ancient Stone 1, magnification $\times 50$, Nicols, (b) Ancient Stone 2, top drum, magnification $\times 100$, Nicols, (c) Italian Restoration stone, magnification $\times 25$, Nicols \pm , (d) Stone from Location A of Rhodes quarry, PAR_Sa, magnification $\times 50$, Nicols \pm , (e) Stone from Location B from Rhodes quarry, PAR_Sb, magnification $\times 50$, Nicols \pm , (f) Spain quarry stone, PAR_Alb, magnification $\times 25$, (g) Cyprus quarry stone, PAR_K, magnification $\times 50$, Nicols \pm Nicols \pm , (h) Achaia quarry stone, PAR_Dask, magnification $\times 50$, Nicols \pm .

Examination of the two ancient stone samples taken from the column of the temple, categorized them as calcarenites (Figure 3a,b) and specifically biocalcarenites. There is an intense presence of 
clastic material, with a large presence of fossils $(>50 \%)$, some of which have been replaced by sparitic and micritic material. Lithic clastic fragments, such as pyrites (amorphous siliceous material), altered igneous rocks (serpentinites, etc.), radiolarites, calcareous fragments, and crystalline fragments, such as astrites, pyroxenes, sediments, quartz and mica leaflets are present, while iron oxides and hydroxides are also sporadically detected. The binding material is characterized as sparitic (cement) and is detected in a small percentage $(<10 \%)$. Both samples presented similar mineralogical characteristics, however less voids were detected in the sample from the upper drum (Ancient stone 2, Figure 3b). The Italian Restoration stone, which was also sampled from the monument, was characterized as a calcarenite (Figure 3c). Its clastic material can be separated into clastic and bioclastic, with the latter having a predominating presence (large percentage of fossils, as well as areas where sparitic and micritic material has substituted fossils). The clastic material present includes lithic fragments (pyrites), as well as crystalline fragments (quartz). Angular agglomerates of micritic material are observed, as well as diffusion of iron oxides and hydroxides. The binding material is characterized as microsparitic.

The lithotypes from both locations of the Rhodes quarry were both characterized as calcarenites and presented similar mineralogical characteristics with the historical stone samples (both ancient and Italian restoration). In particular, an intense presence of clastic material is detected in PAR_Sa (Figure 3d), similarly with the historical stones, while sparse marble fragments are also noticed. In PAR_Sb (Figure 3e) there is an abundance of bioclasts, in some areas substituted by sparitic and micritic material, lithic clastic fragments, as well as crystalline fragments, while iron oxides and hydroxides are sporadically discerned. The binding material of both lithotypes from the Rhodes quarry is sparitic (cement). The stone from the quarry in Spain was also characterized as a calcarenite (Figure 3f). The clastic material present is bioclasts (fossil fragments) and clasts, with the former prevailing. The clastic fraction is mostly crystalline (quartz), while lithic clasts are present in a smaller abundance. The binding material of the stone is characterized as sparitic and is present in a very small percentage, while a large number of voids and pores in the sample is noticed. The stone from the Cyprus quarry is also a calcarenite (Figure $3 \mathrm{~g}$ ). It is rich in clastic material, and specifically lithic clastic fragments, crystalline fragments and bioclasts (fossils), the latter present in small quantity. Iron oxides and hydroxides are noticed sporadically. The binder is characterized as sparitic (cement). The stone from the Achaia quarry is a calcitic sandstone (Figure 3h). There is an abundance of clastic material, with an equal presence of lithic and crystalline fragments, however, in contrast to all other samples, bioclasts are almost absent. Iron oxides and hydroxides are sporadically detected. The binding material is characterized as calcitic.

\subsubsection{X-ray Diffraction Results}

In parallel, mineralogical examination was conducted through $X$-ray diffraction on pulverized samples of each lithotype (Table 1).

Table 1. XRD results of stone samples.

\begin{tabular}{cc}
\hline Stone Sample & Mineralogical Components \\
\hline Ancient Stone 1 & Calcite, aragonite, gypsum, quartz, illite, halite \\
Ancient Stone 2 & Calcite, quartz, aragonite \\
Italian Restoration & Calcite, quartz, halite, aragonite \\
PAR_Sa & Calcite, quartz, ilvaite, kaolinite \\
PAR_Sb & Calcite, quartz, cristobalite \\
PAR_Alb & Calcite, quartz \\
PAR_K & Calcite, quartz, anorthite, montmorillonite, saponite \\
PAR_Dask & Quartz, calcite, albite, anorthite, illite, montmorillonite, cristobalite \\
\hline
\end{tabular}

The principal mineralogical component of all historical stones (both ancient and from the Italian restoration) is calcite. Quartz is the secondary component, without an intense presence, while aragonite is detected in traces in all historical stone samples, serving as secondary mineralogical component in 
the ancient stone sampled from the lower part of the column. In Ancient Stone 1, gypsum is detected, perhaps the result of gypsum dissolution of other materials containing gypsum and transportation through water solution movement into the pores of the stone, but most probably due to the sea spray. In the Italian Restoration stone, as well as in Ancient Stone 1, halite was detected, a result of salt accumulation due to the proximity of the monument to the sea. Illite is detected as trace element in Ancient Stone 1. The presence of aragonite in all three samples taken from the monument could be due to the local marine environment and the use of a local biocalcarenite, as aragonite is formed in such an environment through biological and physical processes.

The principal mineralogical phase of most quarry stones examined is calcite $\left(\mathrm{CaCO}_{3}\right)$, with the exception of the Achaia quarry stone (PAR_Dask), where quartz $\left(\mathrm{SiO}_{2}\right)$ is the dominant mineral present and calcite is detected as the secondary mineralogical phase. The samples from the Rhodes quarry contain quartz as secondary mineralogical component; in the sample taken from Location A (PAR_Sa) ilvaite $\left(\mathrm{CaFe}_{2} \mathrm{FeO}_{2}\left(\mathrm{Si}_{2} \mathrm{O}_{7}\right)\right)$ and kaolinite $\left(\mathrm{Al}_{2} \mathrm{Si}_{2} \mathrm{O}_{5}(\mathrm{OH})_{4}\right)$ are present, while in the sample from Location B (PAR_Sb) cristobalite $\left(\mathrm{SiO}_{2}\right)$ is detected. In the stones from the Achaia and the Cyprus quarry, anorthite $\left(\mathrm{CaAl}_{2} \mathrm{Si}_{2} \mathrm{O}_{8}\right)$ and montmorillonite $\left((\mathrm{Na}, \mathrm{Ca})_{0.33}(\mathrm{Al}, \mathrm{Mg})_{2}\left(\mathrm{Si}_{4} \mathrm{O}_{10}\right)(\mathrm{OH})_{2} \bullet \mathrm{nH}_{2} \mathrm{O}\right)$ are detected in small quantities; in the stone from the Cyprus quarry saponite $\left(\mathrm{Ca}_{0.5}(\mathrm{Mg}, \mathrm{Fe})_{3}\left((\mathrm{Si}, \mathrm{Al})_{4} \mathrm{O}_{10}\right)(\mathrm{OH})_{2} \bullet 4\left(\mathrm{H}_{2} \mathrm{O}\right)\right.$ is also detected, while in the stone from the Achaia quarry, albite $\left(\mathrm{NaAlSi}_{3} \mathrm{O}_{8}\right)$, illite $\left(\mathrm{KAl}_{2} \mathrm{Si}_{3} \mathrm{AlO}_{10}(\mathrm{OH})_{2}\right)$ and cristobalite $\left(\mathrm{SiO}_{2}\right)$ are detected.

Therefore, the petrographic and mineralogical examination of the samples showed that the stones from the Rhodes quarry presented the greatest similarity with the historical stone, while amongst the other quarry stones, the one from Cyprus presented the greatest similarity. The Achaia quarry stone is quite different from the historical, therefore considered highly incompatible, in terms of stone type, with the ancient stone that is to be preserved.

\subsubsection{Thermal Analysis Results}

Thermal analysis (TG/DTA) was conducted on pulverized samples of the historical stones, as well as on pulverized samples of the quarry stones. The results are stated in the following Table (Table 2), as mass loss (\%) at the different temperature ranges:

Table 2. Thermal analysis results (TG/DTA) of historical stones and quarry stones.

\begin{tabular}{cccccc}
\hline \multirow{2}{*}{ Stone Sample } & \multicolumn{3}{c}{ Mass Loss (\%) in the Different Temperature Ranges } & $\mathbf{C a C O}_{\mathbf{3}} \mathbf{\%}$ \\
& $\mathbf{<} \mathbf{1 2 0}{ }^{\circ} \mathbf{C}$ & $\mathbf{1 2 0 - 2 0 0}{ }^{\circ} \mathbf{C}$ & $\mathbf{2 0 0 - 6 0 0}^{\circ} \mathbf{C}$ & $\mathbf{> 6 0 0}{ }^{\circ} \mathbf{C}$ & Content \\
\hline Ancient Stone 1 & 0.05 & 0.03 & 1.11 & 35.96 & 81.80 \\
Ancient Stone 2 & 0.07 & 0.06 & 1.75 & 40.18 & 91.40 \\
Italian Restoration & 0.06 & 0.06 & 2.42 & 38.90 & 88.49 \\
PAR_Sa & 0.38 & 0.32 & 1.71 & 31.93 & 72.63 \\
PAR_Sb & 0.15 & 0.07 & 0.66 & 36.12 & 82.16 \\
PAR_Alb & 0.08 & 0.13 & 0.71 & 37.08 & 84.35 \\
PAR_K & 1.79 & 0.47 & 1.73 & 27.67 & 62.94 \\
PAR_Dask & 0.79 & 0.31 & 1.16 & 8.75 & 19.90 \\
\hline
\end{tabular}

All stones presented low content in physically bound water, as stated by the weight loss (\%) in the temperature range up to $120^{\circ} \mathrm{C}$, except for the stone from the Cyprus quarry, which presents $>1 \%$. This could be attributed to the large amount of binding material present in this lithotype and the consequent moisture uptake. All stones present small mass loss percentages in the temperature range $120-200{ }^{\circ} \mathrm{C}(<0.50 \%)$. In the temperature range $200-600{ }^{\circ} \mathrm{C}$, the Italian Restoration stone presents the highest mass loss ( 2.5\%). The stone from Location B of the Rhodes quarry and the stone from Spain present the smallest mass loss in this range $(<1 \%)$, while both ancient stone samples, the stone from Location A of the Rhodes quarry and the stones from Cyprus and Achaia present intermediate 
values $(\sim 1.1 \%-1.7 \%)$. Mass losses in this range are probably due to the presence of clay minerals and their dehydroxylation.

Almost all samples presented a high mass loss percentage in the temperature range above $600{ }^{\circ} \mathrm{C}$, attributed to the decomposition of calcite and consequent loss of $\mathrm{CO}_{2}$. Ancient Stone 2, the sample from the top drum of the column, presented calcite 91\%, while Ancient Stone 1, from the second to top drum, presented a calcite content of $\sim 82 \%$. This difference could be attributed either to the inhomogeneity of the natural material either to the genesis or transfer and recrystallization of calcite through some process or both. The Italian Restoration stone has a calcite content in between the two ancient stone samples. Regarding the quarry stones, the stone from the quarry in Spain, presented the highest amount of calcite, while the Rhodes quarries samples presented similar values $\left(>30 \% \mathrm{CO}_{2}\right.$ mass loss). The sample from the Cyprus quarry also presented a high amount of calcite, however lower than the previous ones. The sample from the quarry in Achaia presented the lowest percentage of calcite, which was expected taking into account its mineralogical composition. Through DTA, an endothermic peak detected in all samples around $575{ }^{\circ} \mathrm{C}$ is attributed to the transformation of quartz from $\alpha \rightarrow \beta$, which is not accompanied by any mass change. The peak attributed to the decomposition of calcite was noticed at $\sim 850^{\circ} \mathrm{C}$ in all samples, except for the stone from the Achaia quarry, which presented a peak at $\sim 790^{\circ} \mathrm{C}$.

\subsubsection{Mercury Intrusion Porosimetry Results}

Microstructural analysis was conducted through mercury intrusion porosimetry (MIP). The cumulative volume curve in relation to the pore radius of all quarry samples, Ancient Stone 1, from the second to top drum (which was found in an adequate state of preservation and is quite representative of the preservation state of the original stone in the monument) and the stone used during the Italian restoration, found highly disintegrated, are depicted in Figure 4, while the measured microstructural characteristics of all samples are presented in Table 3. It must be stressed that historical materials are disturbed systems and thus their characteristics today are not identical to their characteristics at the time of their application. However, as restoration materials are required to serve adequately with the historical materials with their current characteristics, care must be taken to ensure that any new material will not harm the historical one, and that the restored monument will behave in the most homogenous manner possible, in regard to both hygric and mechanical behavior. The microstructural characteristics of a material play an important role in its behavior, especially regarding water transfer phenomena, susceptibility to decay and salt crystallization and mechanical properties. Similarity between materials in regard to microstructural characteristics is important to ensure homogeneity of the structure. 


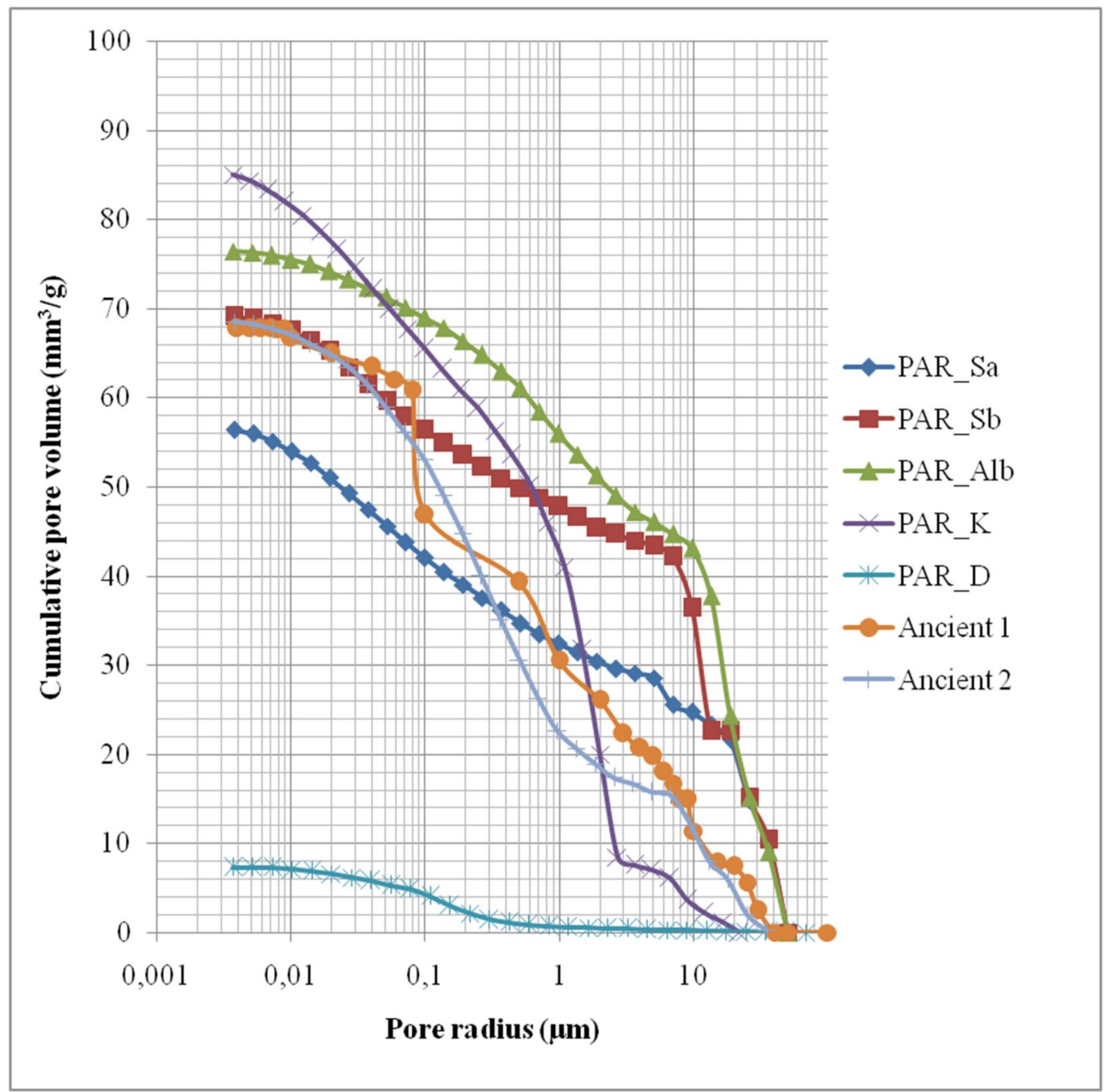

Figure 4. Cumulative pore volume curve in relation to pore radius for quarry and historical stones.

As previously described, the Italian Restoration stone was found in a very bad state of preservation and the Central Archaeological Council has decided to completely substitute this material in the upcoming restoration. Indeed, it presents a higher total cumulative volume and a much higher average pore radius than the ancient stone. These characteristics have a two-fold significance; the Italian stone perhaps from the beginning had a microstructure more susceptible to decay from salt crystallization and at the same time, salt crystallization within the pores and pore fractures have increased the average pore radius and total cumulative volume. This is also expressed through the higher porosity of the Italian stone in relation to the ancient stone. The bulk density of the Italian stone is however similar to the ancient stone.

The ancient stone samples present similar characteristics, however a slightly different pore radius and also a slightly different pore size distribution. As petrographic analysis showed that these two samples are in fact the same lithotype from the same quarry; this difference is due to "inborn" inhomogeneity of the specific lithotype, as well as differential weathering of the stone material in the structure (affected by different microclimate, according to, e.g., orientation, different adjunct materials, e.g., use of cement in certain areas, etc.).

Regarding the quarry stones, it is evident that the Achaia stone (PAR_Dask) is completely incompatible with the ancient stone and in fact with all other stones examined, in relation to all microstructural characteristics, as well as in relation to pore size distribution, presenting an extremely small amount of pores over $10 \mu \mathrm{m}$, as well as between 1-10 $\mu$ min relation to the ancient stone samples, 
at the same time presenting the highest amount of pores in the range $0.01-0.1 \mu \mathrm{m}$ in relation to the ancient stone and all other quarry stones. Therefore, the use of this stone would lead to moisture and salt concentration in the historical material, accelerating its decay. PAR_Sa and PAR_Sb from the Rhodes quarry present a similar pore size distribution. The stones from the Rhodes quarries present a distribution similar to the one presented by the ancient stone, except for the fact that the ancient stone presents somewhat fewer pores with radius over $10 \mu \mathrm{m}$. The stone from the quarry in Spain presented a similar microstructure with the Italian restoration stone, while the stone from Cyprus presents much fewer pores of high radius and a more substantial amount of small radius pores in relation to the ancient stones.

Table 3. Microstructural characteristics of stone samples.

\begin{tabular}{|c|c|c|c|c|c|}
\hline Stone Sample & $\begin{array}{l}\text { Total Cumulative } \\
\text { Volume }\left(\mathrm{mm}^{3} / \mathrm{g}\right)\end{array}$ & $\begin{array}{c}\text { Specific } \\
\text { Surface Area } \\
\left(\mathrm{m}^{2} / \mathrm{g}\right)\end{array}$ & $\begin{array}{c}\text { Average Pore } \\
\text { Radius } \\
\text { (Micron) }\end{array}$ & $\begin{array}{c}\text { Porosity } \\
(\%)\end{array}$ & $\begin{array}{c}\text { Apparent } \\
\text { Density } \\
\left(\mathrm{g} / \mathrm{cm}^{3}\right)\end{array}$ \\
\hline Ancient Stone 1 & 67.72 & 0.58 & 1.55 & 15.10 & 2.23 \\
\hline Ancient Stone 2 & 68.46 & 1.21 & 0.43 & 15.35 & 2.24 \\
\hline Italian Restoration & 82.72 & 1.22 & 6.59 & 18.16 & 2.20 \\
\hline PAR_Sa & 56.59 & 1.36 & 5.21 & 13.03 & 2.30 \\
\hline PAR_Sb & 69.09 & 0.97 & 11.15 & 15.55 & 2.25 \\
\hline PAR_Alb & 76.37 & 0.63 & 10.38 & 16.70 & 2.19 \\
\hline PAR_K & 85.48 & 2.10 & 1.07 & 17.53 & 2.05 \\
\hline PAR_Dask & 7.30 & 0.36 & 0.06 & 1.89 & 2.59 \\
\hline
\end{tabular}

All samples presented similar total cumulative volume values, except for the stone from the Achaia quarry, which presented a distinctly lower value. Ancient Stone 1 presented an average pore radius of $1.55 \mu \mathrm{m}$, while Ancient Stone 2 presented a lower average pore radius of $0.43 \mu \mathrm{m}$. The most similar quarry stone in terms of average pore radius is the one from the Cyprus quarry (PAR_K), which also presents a low average pore radius $(1.07 \mu \mathrm{m})$. The stone from the Achaia quarry presented an extremely low average pore radius, completely incompatible with the ancient stone. The average pore radius of the stones from the two locations of the Rhodes quarry is higher than the ancient stones, with Location B stone presenting double the average pore radius of the stone from Location A. The stone from Spain presents a similar value in this respect with the Rhodes stone from Location B. Porosity values are more or less similar, with the exception of the Achaia stone, where porosity is extremely small (1.89\% in comparison to $15 \%)$. Apparent density values of all stones are similar, except for the Cyprus stone, which presents a lower value than the historical stone, and the Achaia stone, which presents a quite higher apparent density value.

\subsubsection{Capillary Rise Tests}

Water absorption through capillarity of each quarry stone was studied. The capillary rise coefficient of each quarry stone (three cubic specimens from each quarry stone) was estimated in accordance to EN15801. The estimated capillary rise coefficient and water absorption capacity through capillary of each stone type is stated in Table 4, while in Figure 5 typical test results for all quarry stones are depicted, presenting the amount of absorbed water by surface area $\left(\mathrm{g} / \mathrm{cm}^{2}\right)$ in relation to the square root of time $\left(\sec ^{1 / 2}\right)$. 
Table 4. Capillary rise coefficient of each quarry stone and water absorption capacity through capillary rise.

\begin{tabular}{ccc}
\hline Sample Code & $\begin{array}{c}\text { Capillary Water Absorption } \\
\text { Coefficient }\left[\mathrm{kg} / \mathbf{m}^{\mathbf{2}} \cdot \mathbf{s}^{\mathbf{1} / \mathbf{2}}\right]\end{array}$ & Water Absorption Capacity \% \\
\hline PAR_Sa & 0.0125 & 5.18 \\
PAR_Sb & 0.3655 & 8.96 \\
PAR_Alb & 0.3490 & 8.00 \\
PAR_K & 0.0150 & 6.97 \\
PAR_Dask & 0.0053 & 1.46 \\
\hline
\end{tabular}

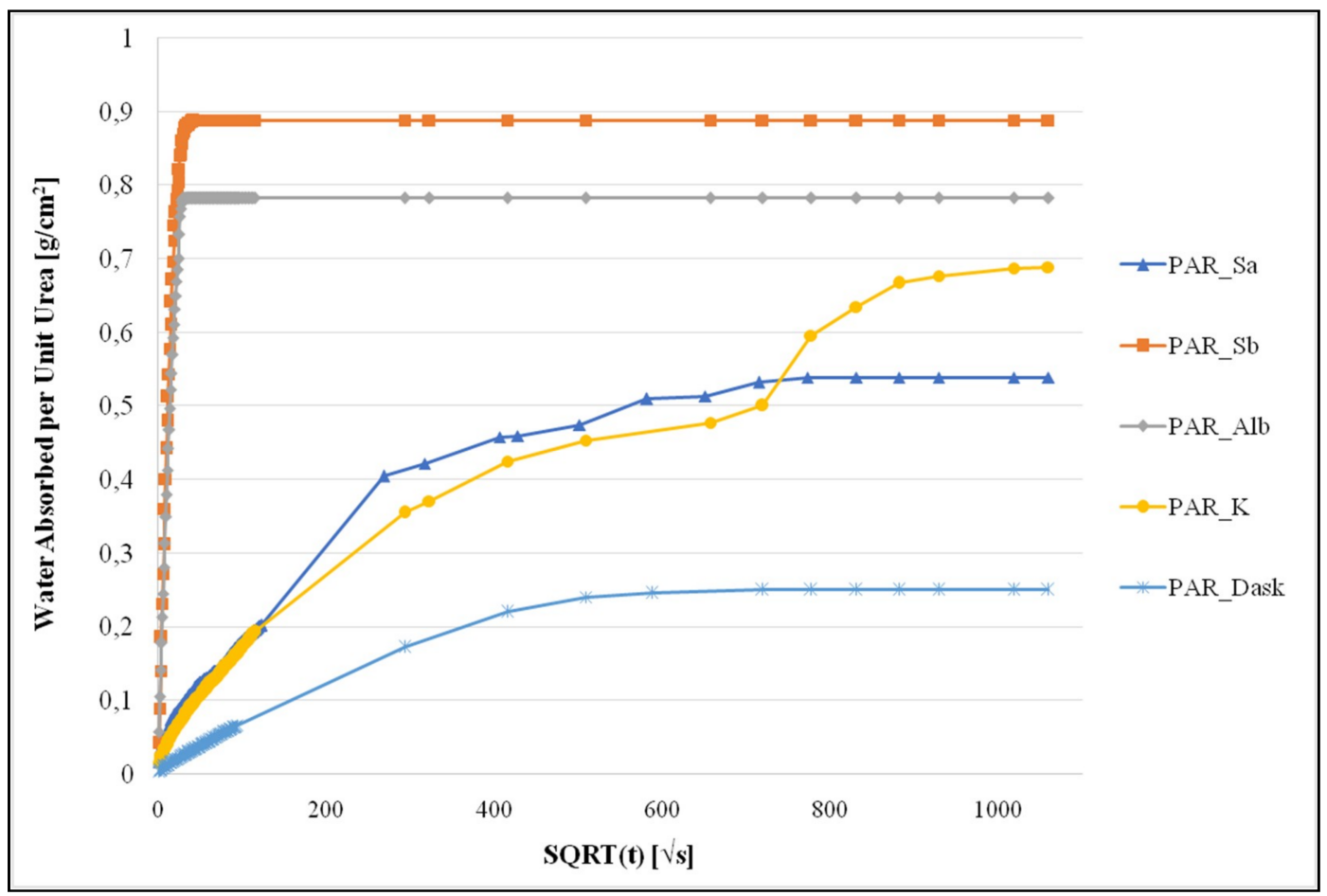

Figure 5. Capillary rise test results for all quarry stones.

EN 15801 includes different exemplary types of capillary rise curves. It is important to notice, that amongst the quarry stones examined, two different types of curves are noticed. The stone from the Rhodes quarry (PAR_Sb), presents a similar type of capillary water absorption curve and a similar coefficient value, with the stone from the Spain quarry. PAR_Sb, presents a higher water absorption capacity than PAR_Alb, both, however, present the highest values of water absorption capacity by capillary pores amongst all quarry stones examined. The stone from the Achaia quarry presents the same type of capillary water absorption curve, but presents a distinctly lower coefficient value and water absorption capacity; in fact, it presents the lowest coefficient and capacity amongst all quarry stones examined. The other quarry stone from Rhodes (PAR_Sa) presents a similar type of curve with the stone from the Cyprus quarry, at the same time presenting similar values of water absorption coefficients and capacity. However, in the case of the Cyprus stone, water uptake through capillary rise seems to happen in two stages, continuing longer than in the case of PAR_Sa, resulting in a higher final value of water absorption capacity $\left(\% \mathrm{WAC}_{\text {cap }}\right)$.

The capillary rise coefficient is extremely important when dealing with outdoors monuments, especially monuments which are in close proximity to the sea, such as the Apollo Pythios Temple. A low capillary rise is desirable, however not to the extent where the new material could cause moisture accumulation in the historical one. In this light, it is obvious that the Achaia quarry stone is deemed inappropriate, due to its extremely low capillary rise coefficient, while the stone from Location B of 
the Rhodes quarry and the stone from the Spain quarry, due to their relatively high capillary rise coefficient, could increase water uptake of the structure.

\subsubsection{Total Immersion Tests}

In addition to capillary water uptake tests, total immersion in water tests were also conducted on both the ancient stone samples and the quarry stones. This was considered a necessity, as, due to sampling limitations, it was not possible to extract a sample of ancient stone large enough in order to conduct capillary rise tests; furthermore, this test provides valuable information in relation to hygric behavior, which is complementary to capillary rise tests. Therefore, the samples were dried until constant mass. The dry mass $\left(\mathrm{m}_{\mathrm{d}}\right)$ was recorded and each sample was placed in a container, covered with deionized water until completely immersed with $2 \mathrm{~cm}$ of water above their upper surface. At programmed intervals, the sample was removed and its mass was recorded. This process was continued until no mass difference was recorded between two successive measurements. The water absorption capacity through total immersion for each material was calculated through the equation:

$$
\mathrm{WAC}=100 \times\left(\mathrm{m}_{\max }-\mathrm{m}_{\mathrm{d}}\right) / \mathrm{m}_{\mathrm{d}}
$$

where $\mathrm{m}_{\max }$ is the maximum mass value recorded during the test. The results are summarized in the following table (Table 5):

Table 5. Total immersion test results for historical stone samples and quarry stone specimens.

\begin{tabular}{cc}
\hline Sample & WAC $_{\mathbf{i m m}} \mathbf{( \% )}$ \\
\hline Ancient Stone 1 & 18.33 \\
Ancient Stone 2 & 9.01 \\
Italian Restoration & 26.54 \\
PAR_Sa & 6.06 \\
PAR_Sb & 9.96 \\
PAR_Alb & 9.46 \\
PAR_K & 7.09 \\
PAR_Dask & 1.31 \\
\hline
\end{tabular}

The two ancient stone samples present a large difference in $\mathrm{WAC}_{\mathrm{imm}}(\%)$ values $(\sim 18 \%$ and $9 \%$ for Ancient Stone 1 and Ancient Stone 2 respectively). This is indicative of the differential weathering of this building material, as well as of the "inborn" inhomogeneity of the specific lithotype. The Italian Restoration stone, which, as already mentioned, is to be removed from the monument, presents an extremely high WAC value in comparison with all other lithotypes. Again, lithotype PAR_Dask presents a highly incompatible behavior with the historical stones, as it has a very low WAC value $(\sim 1 \%)$. All other lithotypes present intermediate values (9\%-10\%) except for, while PAR_Sa and PAR_K present lower values, $\sim 6 \%$ and $\sim 7 \%$ respectively.

\subsubsection{Compressive Strength Measurements}

Due to the legislation and ethics by which cultural heritage protection abides, and taking into account the bad preservation state of the monument and the relatively scarce fragments of historical stone on the Temple, it was not possible to extract specimens large enough to conduct compressive strength measurements of the historical stones. Therefore, in Table 6, the compressive strength values of the quarry stones are stated, as measured in lab, while the compressive strength of the historical stone is included, as estimated through Schmidt hammer tests, conducted in situ [19]. It must be stressed that the value reported is only an estimation of the compressive strength of the historical material. 
Table 6. Average and characteristic compressive strength values of samples.

\begin{tabular}{ccc}
\hline Stone Sample & $\begin{array}{c}\text { Average Compressive } \\
\text { Strength } \mathbf{( M P a )}\end{array}$ & $\begin{array}{c}\text { Characteristic Compressive } \\
\text { Strength (MPa) }\end{array}$ \\
\hline Ancient Stone & $12.00^{*}$ & N/A \\
PAR_Sa & 17.37 & 10.04 \\
PAR_Sb & 30.18 & 3.30 \\
PAR_Alb & 10.81 & 8.19 \\
PAR_K & 19.44 & 17.25 \\
PAR_Dask & 132.10 & 104.96 \\
\hline
\end{tabular}

* This value was not measured according to EN 1926 as the other, but through Schmidt hammer tests [19].

PAR_Sa presents an average compressive strength of $\sim 17 \mathrm{MPa}$, while it presents a characteristic compressive strength value of $10 \mathrm{MPa}$. These values are close to the compressive strength values estimated for the historical stone material. PAR_Sb presents a much higher average compressive strength value ( $30 \mathrm{MPa})$, however an extremely low characteristic compressive strength; this is an indication of high anisotropy of the material and a reason of discarding it as a possible restoration stone in the upcoming restoration. PAR_Alb presents an average compressive strength vale $\sim 11 \mathrm{MPa}$, within the range measured for the historical stone and is therefore the most compatible amongst the quarry stones; however, due to the seismic risk the monument is under, it would be preferable to select a stone of superior mechanical performance in order to achieve the required mechanical performance. PAR_K presents an average compressive strength value of $\sim 19 \mathrm{MPa}$, which a characteristic compressive strength value of $\sim 17 \mathrm{MPa}$, thus showing a relatively high degree of isotropy and homogeneity in relation to compressive strength. Although higher than the estimated compressive strength of the historical stone, these values are considered as compatible; in addition, the use of a material with such mechanical properties would improve mechanical performance of the structure as a whole. PAR_Dask presents an average compressive strength value of $\sim 132 \mathrm{MPa}$, which is much higher than the ancient stone; the use of such a strong material would be detrimental to the historical stone in the case of a dynamic stress event.

\subsubsection{Ultrasound Measurements}

Ultrasound measurements were also conducted on the quarry samples (cubic specimens, $5 \mathrm{~cm}$ $\times 5 \mathrm{~cm} \times 5 \mathrm{~cm}$ ). Ultrasound measurements were conducted on cubic specimens, before subjecting them to typical mechanical strength measurements, as presented directly above. Ultrasound velocity of each lithotype was calculated as the average value measured for all planes, while the lowest ultrasound velocity was also noted (weakest plane). The mechanical tests were conducted utilizing this information, in order to acquire the mechanical strength of the weakest plane of each sample. The results are summarized below (Table 7):

Table 7. Ultrasound measurement results for quarry stones.

\begin{tabular}{ccc}
\hline Sample & $\begin{array}{c}\text { Ultrasound Velocity (Average } \\
\text { per all Planes) }\end{array}$ & $\begin{array}{c}\text { Ultrasound Velocity (Weakest } \\
\text { Plane) }\end{array}$ \\
\hline PAR_Sa & 1063.17 & 1019.93 \\
PAR_Sb & 1188.72 & 1104.56 \\
PAR_Alb & 1036.73 & 1013.68 \\
PAR_K & 2968.31 & 2623.07 \\
PAR_Dask & 4628.54 & 4185.30 \\
\hline
\end{tabular}

PAR_Sa, PAR_Sb and PAR_Alb presented similar values of ultrasound velocity, while there was no considerable difference between the average ultrasound velocity and the lowest ultrasound velocity measured (plane of weakness). PAR_K presented approximately three times higher ultrasound velocity 
than the other stones, while PAR_Dask presented an extremely high ultrasound velocity, almost five times higher than PAR_Sa, PAR_Sb and PAR_Alb.

\subsubsection{Colorimetry Measurements}

Colorimetry measurements were conducted on each of the quarry stone specimens (three specimens for each quarry stone). The average value of the chromatic parameters, $\mathrm{L}^{*}, \mathrm{a}^{*}, \mathrm{~b}^{*}$, was evaluated for each quarry stone and compared with the chromatic parameter values of Ancient Stone 1 (measurements taken only from interior side, not effected by surface deterioration). Total color difference $(\Delta E)$, as described in EN 15886:2010, was found inadequate for the evaluation, due to the different surface texture of the historical sample (irregular surface) and the quarry samples. Therefore, the adjusted total color difference $\left(\Delta \mathrm{E}^{*}{ }_{94}\right)$, was calculated instead, as well as difference in saturation $\left(\Delta \mathrm{C}_{2,1}^{*}\right)$ and difference in hue $\left(\Delta \mathrm{H}_{2,1}^{*}\right)$. The results are stated in Table 8.

Table 8. Colorimetry results of the quarry stones, in comparison to the ancient stone sample.

\begin{tabular}{|c|c|c|c|c|c|c|}
\hline \multirow{2}{*}{ Stone Sample } & \multirow{2}{*}{$\mathbf{L}^{*}$} & \multirow{2}{*}{$a^{*}$} & \multirow{2}{*}{$\mathbf{b}^{*}$} & \multicolumn{3}{|c|}{ In Relation to Ancient Stone 1} \\
\hline & & & & $\Delta \mathrm{E}_{94}^{*}$ & $\Delta \mathrm{C}^{*}{ }_{2,1}$ & $\Delta \mathrm{H}^{*}{ }_{2,1}$ \\
\hline Ancient Stone 1 & 55.63 & 3.94 & 14.06 & $\mathrm{~N} / \mathrm{A}$ & $\mathrm{N} / \mathrm{A}$ & $\mathrm{N} / \mathrm{A}$ \\
\hline PAR_Sa & 67.90 & 2.66 & 10.63 & 12.49 & -3.64 & 0.20 \\
\hline PAR_Sb & 62.24 & 4.67 & 13.36 & 6.77 & 0.44 & 1.74 \\
\hline PAR_Alb & 75.39 & 4.57 & 18.28 & 20.51 & -2.45 & 3.58 \\
\hline PAR_K & 67.01 & 3.47 & 15.41 & 11.24 & 1.20 & 0.79 \\
\hline PAR_Dask & 61.03 & 2.86 & 11.80 & 6.49 & 4.25 & 3.31 \\
\hline
\end{tabular}

The stones from Location $B$ of the Rhodes quarry and the stone from the Achaia quarry present the lowest $\Delta \mathrm{E}^{*}{ }_{94}$, however visually, these stones seem incompatible in terms of color with the ancient stone. Therefore, and taking into account the different surface texture of the stone surfaces which significantly affects lightness (L), it was decided to examine the difference in saturation and the difference in hue $\left(\Delta \mathrm{C}_{2,1}^{*}\right.$ and $\Delta \mathrm{H}_{2,1}^{*}$, respectively). The stone from Location $\mathrm{B}$ of the Rhodes quarry presented the smallest difference in saturation, followed by the Cyprus stone. The stone from the Achaia quarry presented the highest $\Delta C_{2,1}^{*}$ value, in agreement with visual examination observations. The other stones presented intermediate values. Regarding the difference in hue, the stone from Location A of the Rhodes quarry presented the smallest difference with the ancient stone, followed by the stone from the Cyprus quarry. The Achaia stone and the stone from Spain presented the greatest hue difference with the ancient stone, while the stone from Location B of the Rhodes quarry, presented an intermediate value.

\subsection{Study of Restoration Mortar Evolution with Curing and Evaluation}

A restoration mortar has to be designed to meet the demands of the future restoration project which will take place on the Apollo Pythios Temple. Compatibility and performance of the mortar are crucial in order to achieve a sustainable restoration. The desired compressive strength of the restoration mortar was set at $\sim 10-15 \mathrm{MPa}$, in order to ensure compatibility and at the same time achieve the desired level of mortar performance in the structure. For this purpose, three mortar mixes were designed in order to evaluate their characteristics and compliance with the demands of the future restoration, using aerial lime powder CL-90, siliceous sand $(0-2 \mathrm{~mm})$ and pozzolanic additives (Table 9). Metakaolin, a highly reactive pozzolan, was used as the pozzolanic additive in two different percentages, while in one mix a natural pozzolan was used instead of metakaolin, in order to compare their effect on mortar characteristics (Table 7). The percentage of metakaolin was calculated by taking into account the relevant literature and the desired level of compressive strength [32-34]. In addition to the designed mortars, a commercial lime-metakaolin mortar was also tested (coded ME). 
Table 9. Mortar mixes (\% per weight).

\begin{tabular}{ccccc}
\hline $\begin{array}{c}\text { Restoration } \\
\text { Mortar }\end{array}$ & $\begin{array}{c}\text { Lime } \\
\mathbf{( \% )}\end{array}$ & $\begin{array}{c}\text { Metakaolin } \\
\mathbf{( \% )}\end{array}$ & $\begin{array}{c}\text { Natural } \\
\text { Pozzolan (\%) }\end{array}$ & Siliceous Sand (\%) \\
\hline L_M10.5 & 14.5 & 10.5 & 0 & 75 \\
L_M12.5 & 12.5 & 12.5 & 0 & 75 \\
L_NP12.5 & 12.5 & 0 & 12.5 & 75 \\
\hline
\end{tabular}

\subsubsection{Restoration Mortar Fresh State Characteristics}

The lime powder and the pozzolanic additive were mixed together using the appropriate amount of water (which was the amount needed to reach a consistency of $15 \mathrm{~cm}$ on the flow table \pm 1 ) and the sand was then slowly added. Total mixing time was about $3 \mathrm{~min}$ for all mortars. The fresh state characteristics of the mortars are stated in Table 10. Regarding the fresh state characteristics, the increase of metakaolin seemed to have a slightly negative effect on retained water values, which are required to be as high as possible, while the substitution of metakaolin with natural pozzolan, also had a negative effect, with the lime-natural pozzolan mortar presenting the lowest value of retained water. The commercial mortar presented a slightly lower retained water value in comparison to the designed lime-metakaolin mortars. The increase in metakaolin seemed to cause a slight increase in the specific weight value, while, when metakaolin was substituted by natural pozzolan, the specific weight value increased further. The commercial restoration mortar presented the highest specific weight value, thus more material is consumed, and the product is heavier.

Table 10. Fresh state characteristics of mortars.

\begin{tabular}{ccccc}
\hline $\begin{array}{c}\text { Restoration } \\
\text { Mortar }\end{array}$ & $\begin{array}{c}\text { Water/Binder } \\
\text { Ratio }(\boldsymbol{w} / \mathbf{w})\end{array}$ & $\begin{array}{c}\text { Consistency by } \\
\text { Flow Table }(\mathbf{c m})\end{array}$ & $\begin{array}{c}\text { Retained Water } \\
\mathbf{( \% )}\end{array}$ & $\begin{array}{c}\text { Specific Weight } \\
\left(\mathbf{g} / \mathbf{c m}^{\mathbf{3}} \mathbf{)}\right.\end{array}$ \\
\hline L_M10.5 & 1.1 & 15.6 & 92.99 & 1.89 \\
L_M12.5 & 1.1 & 15.5 & 92.42 & 1.90 \\
L_NP12.5 & 0.89 & 15.1 & 89.37 & 1.96 \\
ME & $0.20^{*}$ & 15.6 & 91.93 & 2.02 \\
\hline
\end{tabular}

* Water in relation to total dry mortar and not binder.

After mixing was complete, the mortars were cast into steel molds to obtain prisms $16 \mathrm{~cm} \times 4 \mathrm{~cm} \times 4 \mathrm{~cm}$ in accordance to the European Standard and kept for seven days in high relative humidity conditions (99\%), while afterwards they were kept in standard conditions (relative humidity $65 \%$ ). The mortars were demolded two days after casting. The characteristics of the restoration mortars presented herein are up to 90 days of curing.

\subsubsection{Thermal Analysis Results-Evolution of Chemical Reactions}

Thermal analysis (TG/DTA) was conducted on all mortar samples at 0, 14, 28 and 90 days in order to monitor reactions and especially portlandite consumption. The results show that there is a high consumption of portlandite in all samples, already from 14 days (Table 11). This was expected, especially in the lime-metakaolin mortars, as lime reacts and is thus consumed through the pozzolanic reaction at very early mortar ages. 
Table 11. Analysis (TG) results of examined mortars at two different ages-mass loss (\%) in different temperature ranges.

\begin{tabular}{|c|c|c|c|c|c|c|c|}
\hline \multirow{2}{*}{$\begin{array}{l}\text { Restoration } \\
\text { Mortar }\end{array}$} & \multirow{2}{*}{ Age (days) } & \multicolumn{5}{|c|}{ Mass Loss (\%) in Different Temperature Ranges } & \multirow{2}{*}{$\begin{array}{c}\mathrm{CaCO}_{3} \\
(\%)\end{array}$} \\
\hline & & $<120^{\circ} \mathrm{C}$ & $120-200^{\circ} \mathrm{C}$ & $200-600{ }^{\circ} \mathrm{C}$ & $600-1000{ }^{\circ} \mathrm{C}$ & $\sim 370-470{ }^{\circ} \mathrm{C}$ & \\
\hline \multirow{4}{*}{ L_M10,5 } & 0 & 0.48 & 0.21 & 2.83 & 4.19 & 2.25 & 9.52 \\
\hline & 14 & 1.15 & 1.14 & 2.70 & 7.11 & 0.35 & 16.16 \\
\hline & 28 & 0.99 & 0.95 & 2.21 & 7.61 & 0.25 & 17.30 \\
\hline & 90 & 0.98 & 0.88 & 2.36 & 8.14 & 0.00 & 18.50 \\
\hline \multirow{4}{*}{ L_M12,5 } & 0 & 0.52 & 0.35 & 2.76 & 4.69 & 1.57 & 10.66 \\
\hline & 14 & 1.24 & 1.18 & 2.27 & 5.45 & 0.34 & 12.39 \\
\hline & 28 & 0.93 & 1.02 & 2.11 & 6.52 & 0.21 & 14.82 \\
\hline & 90 & 0.90 & 0.82 & 2.5 & 6.39 & 0.00 & 14.52 \\
\hline \multirow{4}{*}{ L_NP12,5 } & 0 & 0.44 & 0.23 & 3.05 & 4.17 & 2.21 & 9.48 \\
\hline & 14 & 0.65 & 0.60 & 2.51 & 5.63 & 0.98 & 12.80 \\
\hline & 28 & 0.64 & 0.53 & 1.75 & 7.77 & 0.38 & 17.66 \\
\hline & 90 & 0.55 & 0.44 & 2.16 & 7.39 & 0.12 & 16.80 \\
\hline \multirow{4}{*}{ ME } & 0 & 0.31 & 0.13 & 2.57 & 2.85 & 1.36 & 6.48 \\
\hline & 14 & 0.87 & 0.84 & 2.33 & 4.38 & 0.22 & 9.95 \\
\hline & 28 & 0.83 & 0.73 & 2.24 & 5.07 & 0.00 & 11.52 \\
\hline & 90 & 0.87 & 0.67 & 2.44 & 6.02 & 0.00 & 13.68 \\
\hline
\end{tabular}

The percentage of portlandite at 0 days, as calculated through the mass loss in the temperature range $\sim 370-470{ }^{\circ} \mathrm{C}$ (of course, as portlandite presence decreases, so does the aforementioned temperature range), is in direct association with the addition of lime in the original mix. Therefore, as expected, L_M12.5 presents a lower percentage of portlandite at this age in relation to L_M10.5, due to the smaller percentage of lime in the original mix. The commercial lime-metakaolin mortar presents the lowest amount of portlandite at 0 days in relation to all other mixes. A time proceeds, portlandite is diminished, as expected, as it reacts towards the formation of calcite (through carbonation process) and the formation of hydraulic compounds (through the pozzolanic reaction). Already at 14 days, most samples present a high consumption of portlandite, while at 90 days no mass loss is attributed to portlandite dehydroxilation, therefore all portlandite has reacted, except for the case of the natural pozzolan mortar. In the case of the commercial lime-metakaolin mortar, no portlandite is detected already from 28 days.

Calcite content, which is calculated through the respective mass loss $(\%)$ over $600{ }^{\circ} \mathrm{C}$, increases for all mortars with mortar specimen age. When the percentage of metakaolin is increased in the mixture, the percentage of calcite is decreased. This is expected, on the one hand due to the pozzolanic reaction and the formation of hydraulic compounds rather than calcite (mass loss in temperatures $>600{ }^{\circ} \mathrm{C}$, attributed to the loss of $\mathrm{CO}_{2}$ from calcite decomposition) as curing proceeds, and, on the other hand due to the smaller addition of lime in the original mix. The highest amount of calcite is determined in the lime-metakaolin mortar with the lower percentage of metakaolin, while the lowest is determined in the commercial lime-metakaolin mortar (at 90 days curing). The lime-natural pozzolan mortar presents a calcite content intermediate of the two lime-metakaolin mortars; although the lime-pozzolan ratio is the same for L_M12.5 and L_NP12.5, the lower pozzolanic reactivity of the natural pozzolan has led to a higher amount of calcite formation (14.52\% calcite for L_M12.5 in comparison with $16.80 \%$ calcite content for L_NP12.5 respectively, at 90 days).

The formation of hydraulic compounds can be monitored by the mass losses between $120-200{ }^{\circ} \mathrm{C}$ and $200-600{ }^{\circ} \mathrm{C}$, of course after subtracting the mass loss attributed to portlandite dehydroxilation. Specifically, the aforementioned mass losses (\%) are attributed to water bound in hydraulic compounds. One must of course take into consideration, that in the aforementioned temperature range, hydrated interlayer cations are also detected. In any case, the mass loss in these temperatures is interlinked with the loss of bound water, in contrast to physically bound. In the case of the commercial lime-metakaolin mortar, the amount of water bound increases with time, as the pozzolanic reaction proceeds. For all other mortars, the mass loss, and therefore the amount of bound water, increases substantially 
from 0 days to 14 days, decreases from 14 to 28 days and increases again until 90 days, revealing the complexity of the parallel hardening process within a mortar during the hardening process. At 90 days, were the mortar have somewhat stabilized, the natural pozzolan mortar presents the lowest amount of bound water, while the lime-metakaolin mortar L_M12.5 presents the highest value.

The inverse hydraulicity ration (calculated as the ratio of $\% \mathrm{CO}_{2}$ loss to the water chemically bound to hydraulic compounds\%-excluding of course the mass loss attributed to portlandite dehydroxilation), which is an indication of a mortar's hydraulic nature (decreasingly lower indices correspond to increasingly more hydraulic mortars), is also to be taken into consideration [35]. All mortars at 90 days age present low inverse hydraulicity ratios $(<7.5$, which is considered as a threshold over which mortars with siliceous aggregates are considered as lime mortars according to Reference [35]). Specifically, the lime-metakaolin mortars, L_M10.5 and L_M12.5 present values of 2.51 and 1.92 respectively; the higher percentage of metakaolin, as expected, led to a more hydraulic mortar with a lower inverse hydraulicity ration. The lime-natural pozzolan mortar presents an inverse hydraulicity ratio of 2.98, which is the highest among the examined mortars; this is also expected, as the natural pozzolan presents lower pozzolanicity than metakaolin. The commercial lime-metakaolin mortar presents the same inverse hydraulicity ratio with L_M12.5 (1.94).

\subsubsection{Specific Conductivity and $\mathrm{pH}$ Measurements Results}

Specific conductivity measurements, and respective calculation of total soluble salts content (\%), TSS\% in accordance to [36], as well as Ph measurements, in order to examine the basicity of the mortars, were also conducted on the mortar specimens at different ages (Table 12). An early stabilization of these values are important in order to avoid the development of a dynamic environment between the different building materials of the monument, as well as to ensure that the calcitic ancient stone is not affected by a very high basicity for too long (due to the presence of portlandite), until the chemical reactions of the mortars' hardening processes are complete. As there is no standard procedure for the measurement of $\mathrm{pH}$ of lime-based mortars, the values can serve as relative values in order to compare different mortar mixes.

Table 12. TSS\% and Ph of different mortar samples in relation to age of mortar specimen.

\begin{tabular}{ccccccccc}
\hline \multirow{2}{*}{$\begin{array}{c}\text { Mortar } \\
\text { Samples }\end{array}$} & \multicolumn{9}{c}{ TSS\% } & \multicolumn{3}{c}{ pH } \\
\cline { 2 - 9 } & 0 days & 14 days & 28 days & 90 days & 0 days & 14 days & 28 days & 90 days \\
\hline L_M10,5 & 14.52 & 4.58 & 4.78 & 3.26 & 10.29 & 9.26 & 9.42 & 9.16 \\
L_M12,5 & 12.46 & 8.09 & 3.75 & 3.46 & 10.41 & 9.62 & 9.32 & 8.70 \\
L_NP12,5 & 24.16 & 12.43 & 3.03 & 2.62 & 11.03 & 9.79 & 9.33 & 8.17 \\
ME & 23.50 & 5.99 & 3.08 & 2.69 & 10.56 & 9.40 & 9.15 & 8.70 \\
\hline
\end{tabular}

The extremely high values of calculated soluble salts at 0 days, is attributed to the presence a high amount of unreacted portlandite. At 0 days the natural pozzolan and the commercial lime-metakaolin mortar present total soluble salts values almost twice than the lime-metakaolin mortars. As time progresses and the chemical reactions connected to setting and hardening proceed, the calculated total soluble salts also decrease. By 14 days there is a considerable decrease in all mortar mixes, as they all presented values lower than 10\%, except for the natural pozzolan mortar (L_NP12.5), a result which is in accordance with the thermal analysis results, were this mortar mix present the highest amount of mass loss associated with the dehydroxilation of $\mathrm{Ca}(\mathrm{OH})_{2}$. However, at 90 days, this mortar mix presents the lowest amount of soluble salts, even though a small amount of unreacted portlandite remains. At 90 days, the lime-metakaolin mortars present TSS\% values slightly over the value of 3, while the lime-natural pozzolan mortar and the commercial lime-metakaolin mortar present values under 3.

In relation to $\mathrm{pH}$ all mortars present values $>10$ at 0 days, again connected to the presence of unreacted portlandite of the lime. As time proceeds, $\mathrm{pH}$ values decrease. At 14 days all samples 
present $\mathrm{pH}$ lower than 10 , while at 90 days, all samples present values between 8 and 9 , except for L_M10.5, which presents a value slightly higher than 9 (9.16).

\subsubsection{Capillary Rise Tests}

Capillary rise tests were conducted on cubic specimens of the mortar samples in order to examine their hygric behavior in relation to water uptake through capillarity. The measurements were conducted in accordance to EN 15801 (2010). Characteristics water uptake curves of the examined materials are presented in Figure 6, while Table 13 summarizes the capillary test results and specifically the C.R.C. (capillary rise coefficient) and the $\mathrm{WAC}_{\text {cap }}(\%)$ which corresponds to the percentage of water uptake in relation to the dry mass of the sample before testing.

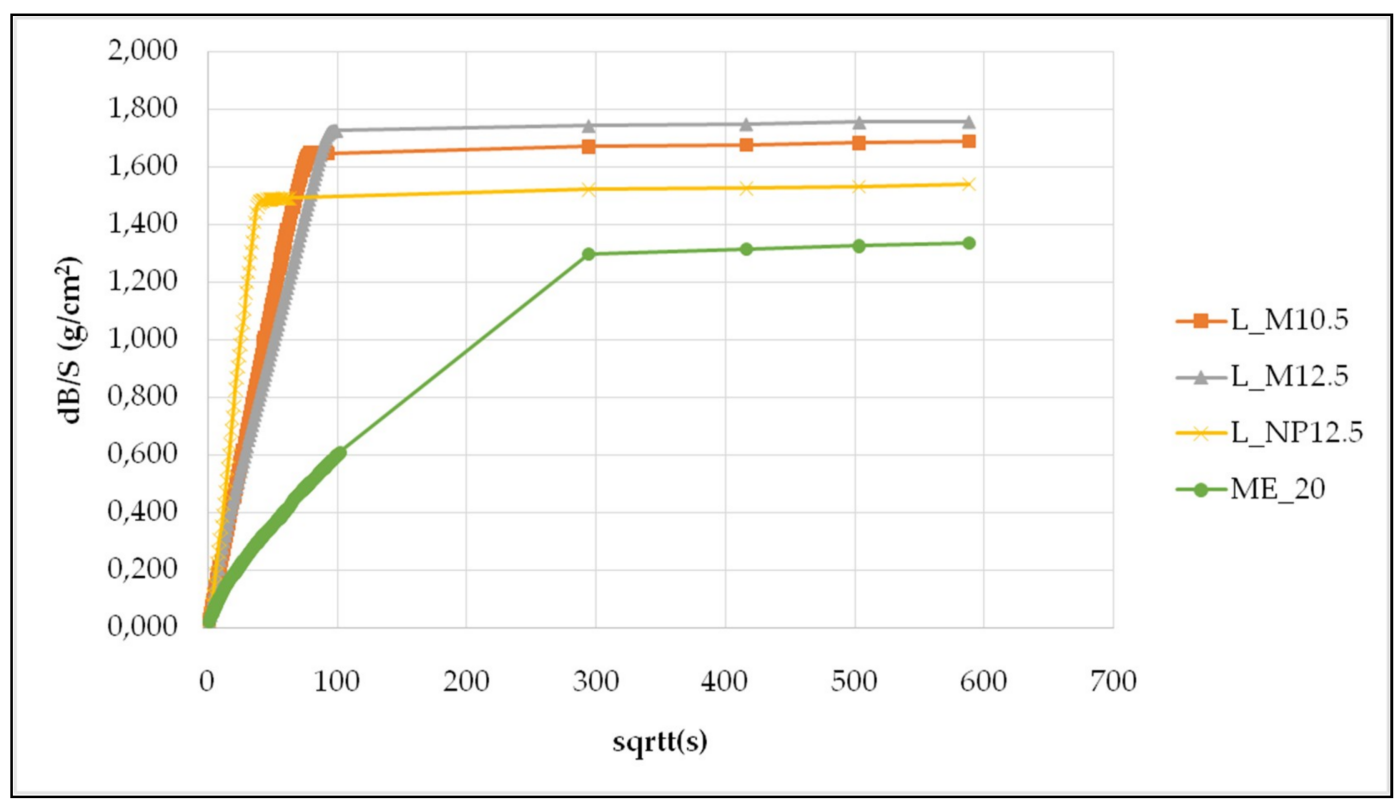

Figure 6. Characteristic capillary rise test results for each mortar mix.

Table 13. Rise tests results-Restoration mortars at 90 days.

\begin{tabular}{ccccc}
\hline Sample & C.R.C. $\left(\mathbf{k g} /\left(\mathbf{m}^{\mathbf{2}} \mathbf{s}^{\mathbf{1 / 2}}\right)\right)$ & StDev & WAC $_{\text {cap }} \mathbf{( \% )}$ & StDev \\
\hline L_M10,5 & 0.2030 & 0.016 & 21.47 & 0.06 \\
L_M12,5 & 0.2060 & 0.023 & 21.48 & 0.17 \\
L_NP12,5 & 0.3580 & 0.052 & 17.97 & 0.14 \\
ME & 0.0650 & 0.010 & 14.85 & 0.06 \\
\hline
\end{tabular}

The two lime-metakaolin mortars present almost identical values; this is an indication that the small difference in metakaolin percentage does not significantly affect hygric behavior. The natural pozzolan mortar presents a much higher, however within the same range, capillary rise coefficient, while at the same time, it presents a lower percentage of water uptake in relation to initial dry mass after saturation through capillarity. The commercial lime-metakaolin mortar presents the lowest values regarding both parameters and is of a different range. The optimum hygric behavior is displayed by a mortar which will not aggravate water uptake of the structure as a whole, but will also display a homogenous behavior in relation to the other building materials.

\subsubsection{Total Immersion Measurements}

In addition to capillary rise tests, total immersion tests were also conducted in accordance to the procedure described in the respective Section 3.1.6. The results are summarized in the following table (Table 14): 
Table 14. Total immersion test results for designed mortars at 90 days.

\begin{tabular}{cc}
\hline Sample & WAC $_{\text {imm }}(\mathbf{\%})$ \\
\hline PAR_L_M10,5_3m & 22.62 \\
PAR_L_M12,5_3m & 23.08 \\
PAR_L_NP12,4_3m & 19.69 \\
PAR_ME_3m & 15.48 \\
\hline
\end{tabular}

The commercial lime-metakaolin mortar presents the lowest value of water absorption capacity through total immersion, while the lime-metakaolin mortars present the highest values. The values of the two lime-metakaolin mortars is very similar, with the mortar mix with increased metakaolin addition presenting a slightly higher value. The lime-natural pozzolan mortar presents a behavior intermediate of the lime-metakaolin mortars and the commercial lime-metakaolin mortar.

\subsubsection{Flexural and Compressive Strength of Restoration Mortars}

Flexural and compressive strength measurements were conducted at 14, 28 and 90 days of curing (Table 15).All mortar mixes present flexural strength values above $1 \mathrm{MPa}$, already from 14 days age, except for the lime-natural pozzolan mortar; in fact the lime-natural pozzolan mortar presents about half the flexural strength of the other mortar mixes. The commercial lime-metakaolin mortar presents the highest values of flexural strength at all ages, while at three months it presents an average value over $2 \mathrm{MPa}$. Flexural strength increases with mortar age for all specimens up to 90 days, except for the lime-metakaolin mortar L_M12.5, where a decrease is noticed from 28 to 90 days. This is expected, as it is noticed than lime-metakaolin mortars acquire high values at early ages and then present a decrease in mechanical strength at higher ages. Compressive strength of the mortars presents a similar trend. Already from 14 days all mortars present adequate values of compressive strength, above $7 \mathrm{MPa}$, except for the lime-natural pozzolan mortar, which presents less than half this value. The commercial lime-metakaolin mortar presents the highest compressive strength value at all ages. Compressive strength increases with mortar age for all mortar mixes, except for the two lime-metakaolin mortars, were a decrease is observed from 28 days to 90 days.

Table 15. Flexural, compressive strength values of restoration mortars with standard deviation.

\begin{tabular}{cccccc}
\hline $\begin{array}{c}\text { Restoration } \\
\text { Mortar }\end{array}$ & $\begin{array}{c}\text { Age } \\
\text { (days) }\end{array}$ & $\begin{array}{c}\text { Average Flexural } \\
\text { Strength (Mpa) }\end{array}$ & St.Dev. & $\begin{array}{c}\text { Average Compressive } \\
\text { Strength (MPa) }\end{array}$ & St.Dev. \\
\hline \multirow{2}{*}{ L_M10,5 } & 14 & 1.11 & 0.07 & 6.17 & 0.46 \\
& 28 & 1.53 & 0.11 & 7.78 & 0.31 \\
& 90 & 1.67 & 0.28 & 6.33 & 0.39 \\
\hline \multirow{2}{*}{ L_M12,5 } & 14 & 1.13 & 0.05 & 6.77 & 0.12 \\
& 28 & 1.67 & 0.07 & 7.93 & 0.16 \\
\hline \multirow{2}{*}{ L_NP12,5 } & 90 & 1.57 & 0.29 & 1.13 & 0.05 \\
& 14 & 0.59 & 0.03 & 2.48 & 0.23 \\
\hline & 28 & 0.77 & 0.12 & 2.92 & 0.26 \\
\hline
\end{tabular}

Therefore, the performance of all mortars is considered adequate, as they acquire early strength, a necessity in such a restoration and in an area of such high seismicity as Rhodes is and also reach an adequate value of compressive strength at 90 days (all mortars, over $7 \mathrm{MPa}$ ). It is interesting that at 90 days, the two lime-metakaolin mortar present similar mechanical strength values; this is an indication that above a certain amount of added metakaolin in relation to lime, no difference is 
noticed (differences are within standard deviation). The commercial lime-metakaolin mortar presents the highest level of mechanical performance, acquiring compressive strength higher than $10 \mathrm{MPa}$ at 90 days.

\subsubsection{Ultrasound Measurements}

In parallel, ultrasound measurements were also conducted on $5 \mathrm{~cm} \times 5 \mathrm{~cm} \times 5 \mathrm{~cm}$ specimens of the designed mortars. The results are summarized below (Table 16) and refer to the average ultrasound of each mortar, considering all planes, as well as the ultrasound velocity of the condensation plane alone:

Table 16. Ultrasound measurement results for restoration mortars.

\begin{tabular}{ccc}
\hline Sample & $\begin{array}{c}\text { Ultrasound Velocity } \\
\text { (Average per All Planes) }\end{array}$ & $\begin{array}{c}\text { Ultrasound Velocity } \\
\text { (Condensation Plane) }\end{array}$ \\
\hline L_M10,5 & 1976.92 & 1897.20 \\
L_M12,5 & 1944.96 & 1866.79 \\
L_NP12,5 & 1729.31 & 1667.94 \\
ME & 2270.93 & 1978.56 \\
\hline
\end{tabular}

The lime-natural pozzolan mortar presents the lowest ultrasound velocity value among all mortar mixes, which is in accordance to compressive strength measurements. The commercial lime-metakaolin mortar presented the highest ultrasound velocity values. The lime-metakaolin mortars present intermediate values of the two. It should be noted that all mortars presented ultrasound velocity values within the relatively tight range $\sim 1950 \mathrm{~m} / \mathrm{s}$ to $2270 \mathrm{~m} / \mathrm{s}$. Furthermore, it should also be noted that the ultrasound velocity measured on the condensation plane (which was also the plane by which the samples were tested for compressive strength) is lower in all cases than the average value calculated when taking all planes into account; it is lower by $\sim 4 \%$, except for the case of the commercial lime-metakaolin mortar, where it is lower by $\sim 12 \%$, therefore within a reasonable range.

\subsubsection{Aesthetic Compatibility of Restoration Mortar}

In order to achieve aesthetic compatibility of the restoration mortar, several different pigments were added to the commercial lime-metakaolin mortar, in order to examine their effectiveness in achieving chromatic compatibility with the ancient stone (Figure 7). Pigment addition is presented in Table 17 (the percentage stated is by weight to the total dry mortar weight) along with the colorimetry results of the pigmented restoration mortars, in comparison to the ancient stone sample.

The addition of cassia resulted in a restoration mortar with the lowest $\Delta \mathrm{E}^{*} 94$, however, as was the case of the quarry stones, this was contradicted by visual observation. Therefore, it was decided to examine the difference in saturation $\Delta C^{*} 1,2$ instead, as well as the difference in hue $\left(\Delta H^{*} 2,1\right)$. The lowest saturation difference with the ancient stone's color parameters is achieved with the addition of $0.5 \%$ burnt obra and $0.25 \%$ ochre. The specific addition also achieved the second lowest value in relation to hue difference with the ancient stone. These results confirmed visual observations and thus it is advised to add these pigments in the aforementioned percentages, at least as final layer of any mortar application, aiming to achieve aesthetic compatibility. 

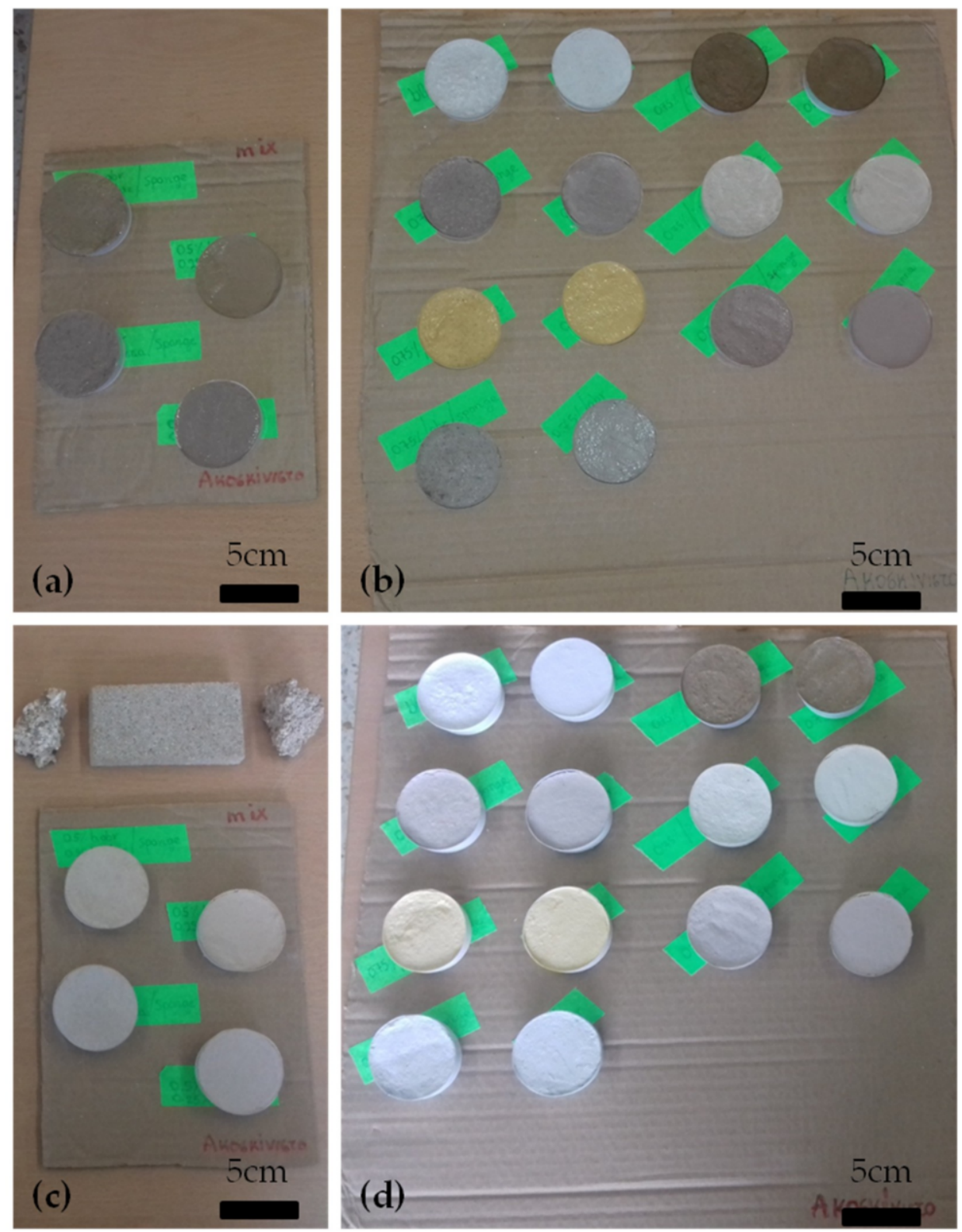

Figure 7. Pigmented mortar samples (commercial restoration mortar with pigments) $(\mathbf{a}, \mathbf{b})$ immediately after mortar production - in fresh state, $(\mathbf{c}, \mathbf{d})$ at 90 days mortar age.

Table 17. Colorimetry results of the quarry stones, in comparison to the ancient stone sample.

\begin{tabular}{|c|c|c|c|c|c|c|}
\hline \multirow{2}{*}{$\begin{array}{c}\text { Pigmented Restoration } \\
\text { Mortar }\end{array}$} & \multirow{2}{*}{$\mathbf{L}^{*}$} & \multirow{2}{*}{$a^{*}$} & \multirow{2}{*}{$\mathbf{b}^{*}$} & \multicolumn{3}{|c|}{ In Relation to the Ancient Stone } \\
\hline & & & & $\Delta \mathrm{E}^{*}{ }_{94}$ & $\Delta C_{2,1}^{*}$ & $\Delta \mathrm{H}_{2,1}^{*}$ \\
\hline without pigment & 87.51 & 0.09 & 4.14 & 32.85 & -10.46 & 1.96 \\
\hline $0.75 \%$ cassia & 57.43 & 7.34 & 18.47 & 3.77 & 5.28 & 1.78 \\
\hline $0.75 \%$ burnt obra & 70.73 & 4.83 & 9.41 & 15.46 & -4.03 & 2.49 \\
\hline $0.75 \%$ sienna & 81.94 & 2.29 & 10.95 & 26.41 & -3.41 & 0.85 \\
\hline $0.75 \%$ ochre & 77.15 & 8.26 & 31.28 & 23.32 & 17.75 & 0.32 \\
\hline $0.75 \%$ burnt sienna & 73.13 & 6.82 & 10.30 & 17.90 & -2.25 & 4.17 \\
\hline $0.75 \%$ obra & 76.98 & 0.36 & 5.95 & 22.27 & -8.64 & 1.99 \\
\hline $0.5 \%$ burnt obra; $0.25 \%$ ochre & 67.53 & 5.17 & 15.51 & 11.96 & 1.74 & 0.75 \\
\hline $0.5 \%$ burnt obra; $0.25 \%$ sienna & 74.20 & 4.41 & 9.80 & 18.80 & -3.85 & 1.88 \\
\hline
\end{tabular}




\section{Discussion}

When deciding upon the selection of a lithotype, which is to be used in a restoration project, compatibility between the new stone and the historical/ancient stone is of paramount importance; however, as Greece is a country of high seismic risk, compatibility must always be accompanied by the appropriate level of performance, in order to avoid failure of the structure and to achieve sustainability. The same is true when selecting the restoration mortar, which is to be used to join together either ancient stone members or new stone members or new stone members with historical stone members. In the present study, as presented in the previous sections, a number of techniques were applied, each one providing valuable information, crucial for the assessment of compatibility between the historical stone and the restoration materials, as well as between the restoration materials themselves (new stone and restoration mortar) (Figure 8). In the present section the results of the previous sections will be summarized and discussed, aiming to highlight compatibility and performance issues, which, if properly addressed, can ensure sustainable preservation of a monument. The importance of using many complimentary techniques is highlighted, as their combination is necessary in order to obtain all required information for decision making.

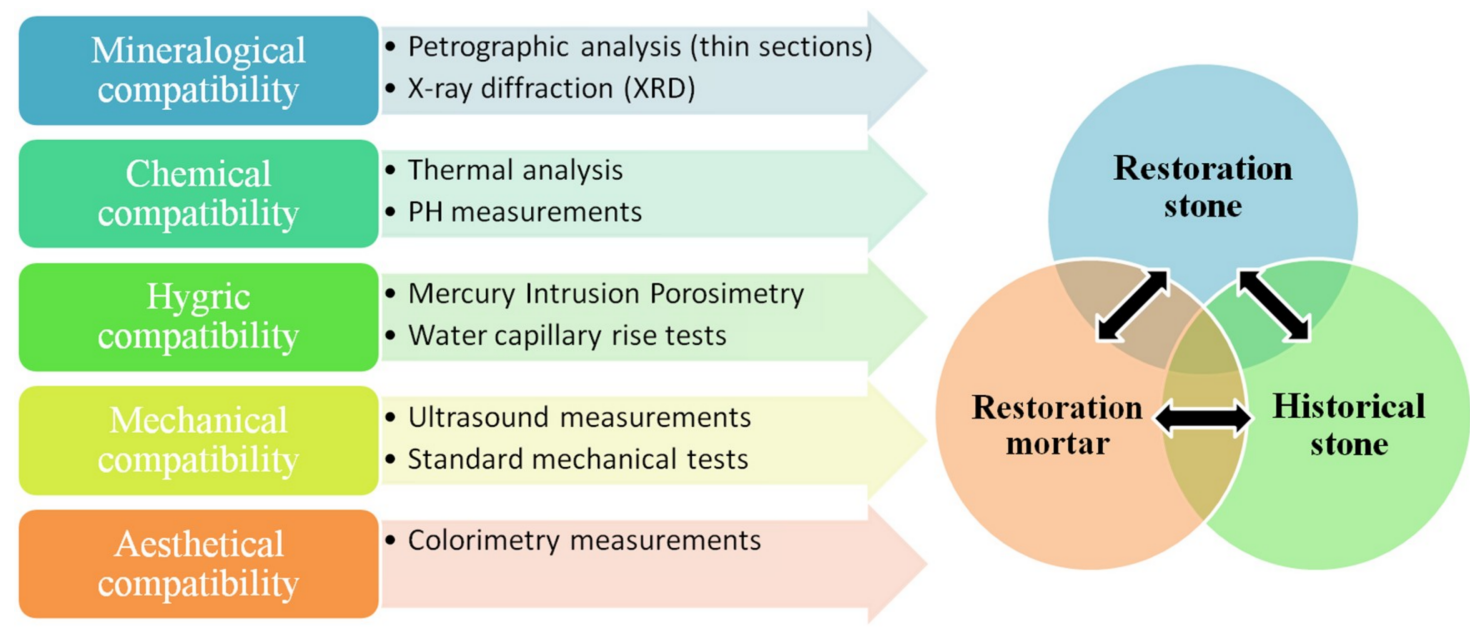

Figure 8. Schematic representation of compatibility aspects and associated measurements.

\subsection{Assessment in Terms of Petrographic and Mineralogical Characteristics}

Petrographic analysis offers a wide range of information regarding a stone sample examined, which is indirectly interlinked with different lithotype properties. In conservation, especially when dealing with important stone monuments, it is important to select restoration stones which are as similar as possible to the original; this not only ensures compatibility between historical and restoration stone, but is also interlinked with preserving the historic value of the monument, as it ensures continuity of material use, associated with technological and material aspects of the monument's construction era. From the petrographic analysis of the different lithotypes' thin sections (Figure 3), assisted by the X-ray diffraction analysis results (Table 1), it is obvious that the PAR_Dask lithotype is incompatible in terms of petrographic similarity, while the other lithotypes present a satisfactory level of similarity. In summary, the similarity of the restoration stones with the ancient stones, in diminishing similarity order, is as follows: PAR_Sa $>P A R \_S b>P A R \_A l b>P A R \_K$. PAR_Dask is not included in the sorting, as it is considered incompatible in this sense; in addition to quite different petrographic characteristics, it is the only lithotype which does not present calcite as a principal mineralogical component. 


\subsection{Assessment in Terms of Chemical Compatibility}

Comparing the thermal analysis results of the ancient stone samples with the restoration stones (Table 2), and especially the calcite content, it is obvious that PAR_Sb and PAR_Alb are in the same range of $\mathrm{CaCO}_{3}$ content as the ancient samples, above $80 \%$. It is interesting that Ancient Stone 2, which is in a worse state of preservation than Ancient Stone 1, presents a higher percentage of $\mathrm{CaCO}_{3}$ content. As petrographic analysis showed that these samples are the same type of stone, from the same quarry, it is obvious that the difference is interlinked with the endogenous inhomogeneity of this lithotype, as well as with deterioration mechanisms which have altered it. PAR_Sa presents a lower $\mathrm{CaCO}_{3}$ percentage, however not much lower (72.63\%), while the PAR_K lithotype from Cyprus presents an even lower percentage (62.94\%). Although all aforementioned samples present over 50\% calcite content, therefore calcite is predominant in the chemical composition, PAR_Dask presents an extremely low calcite percentage, 19.9\%. Another important aspect is the percentage of physically bound water, as measured through thermal analysis, which is expressed as the mass loss $(\%)$ detected in the temperature range $30-120^{\circ} \mathrm{C}$ and which is associated with the physical absorption of humidity of the lithotype when in equilibrium with the environment. In terms of physically bound water, all lithotypes present low percentages, under 1\%, except PAR_K, which presents a higher percentage. In particular, in decreasing similarity the stones are assessed in terms of hygroscopicity as: PAR_Alb $>P A R \_S b>P A R \_S a>P A R \_D a s k>P A R \_K$. The mass loss in the temperature range $120-200{ }^{\circ} \mathrm{C}$, which is associated with the loss of water from hygroscopic salts and hydrated interlayer cations, is more or less in agreement with the above sorting.

Therefore, in terms of diminishing similarity between the restoration stones and the ancient stone samples, the following is concluded: PAR_Alb PAR_Sb $>P A R \_S a>P A R \_K$. PAR_Dask is not included, as it presents a $\mathrm{CaCO}_{3}$ content of a different range $(<50 \%)$.

Regarding the assessment of the restoration mortars in terms of chemical compatibility, the early consumption of portlandite is of paramount importance. The presence of portlandite, causes high specific conductivity, creating dynamic conditions between different materials, and a higher hydrogen potential $(\mathrm{pH})$, which can prove damaging for calcareous substrates. In the following figure (Figure 9) the percentage of portlandite consumption in relation to the portlandite percentage at 0 days of each mortar mix $\left[\left(\mathrm{M}_{0 \text { days }}-\mathrm{M}_{\mathrm{t}}\right) / \mathrm{M}_{0 \text { days }}{ }^{*} 100 \%\right)$ is illustrated in relation to mortar age.

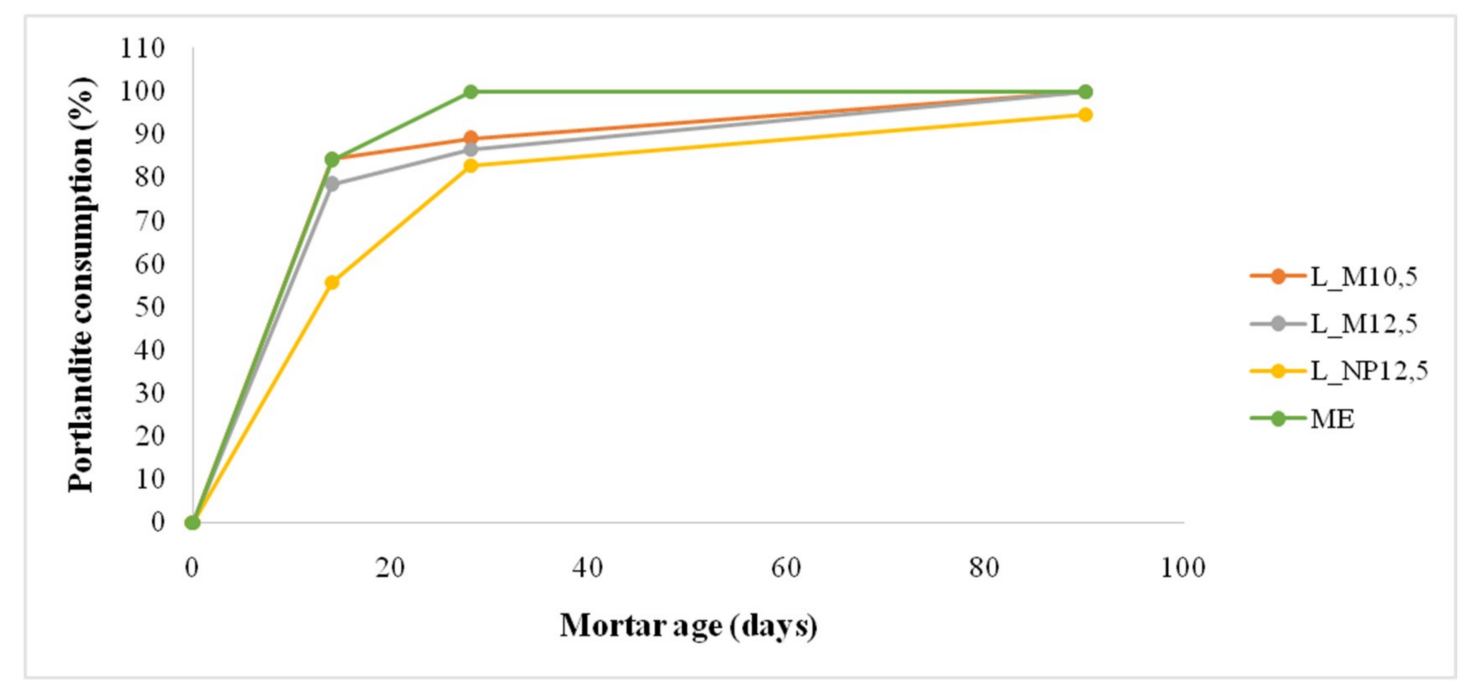

Figure 9. Relative portlandite consumption (\%) in relation to mortar age.

The fast consumption of portlandite for the lime-metakaolin mortars and the commercial mortar is obvious, while the lime-natural pozzolan mortar presents a lower consumption rate at early ages. At 90 days all mortars have consumed portlandite through carbonation and pozzolanic reactions, except 
for the natural pozzolan mortar, which still presents a small amount of portlandite. Therefore, sorting the mortars in respect to portlandite consumption, in terms of highest consumption to lowest, the following is derived: $M E>L \_M 12.5 \sim L \_M 10.5>L \_N P 12.5$.

As mentioned above, $\mathrm{pH}$ values are important, especially when dealing with the restoration of historical stone monuments, especially calcareous stone, as high hydrogen potential can damage calcite. In parallel, early stabilization of $\mathrm{pH}$ and soluble salts values, of course when stabilized values are acceptable, assist in avoiding the creation of dynamic conditions between the material of the stone members to be conserved and the applied restoration mortar. As illustrated in Table 10, already from 28 days the TSS\% calculated are very low in relation to 0 days, while at 90 days, the natural pozzolan mortar and the commercial lime mortar present the lowest values of TSS\%. In terms of soluble salts content, the sorting of the mortar mixes is (in order of increasing TSS\%): L_M12.5<LM10.5<ME<L_NP12.5, at 0 days; LM10.5<ME<L_M12.5<L_NP12.5 at 14 days; $L \_N P 12.5<M E<L \_M 10.5<L \_M 12.5$ at 90 days. Therefore, it is obvious that the sorting has completely reversed from 0 days to 90 days, marking the natural pozzolan as most appropriate in terms of TSS\% at 90 days. However, it should be noted that TSS\% values of all mortar mixes at 90 days are within acceptable limits.

In order to assess the measured $\mathrm{pH}$ values, the $\mathrm{pH}$ value of $100 \mathrm{mg}$ of pure calcite was measured in lab, after adding $100 \mathrm{~mL}$ of water and letting the solution rest for $24 \mathrm{~h}$. As mentioned in the respective section, this was the process followed for the mortar samples as well. Therefore, the pure calcite value can serve as a reference value in relation to requested $\mathrm{pH}$ mortar values. The pure calcite presented a $\mathrm{pH}$ value of 8.82 . The same process was conducted to study the $\mathrm{pH}$ value of the aerial lime powder alone, which presented a $\mathrm{pH}$ value of 11.97 . Taking into account the values presented in Table 12, it is obvious that at 0 days all mortars present high $\mathrm{pH}$ values due to the presence of unreacted portlandite (values between 10.29-11.03), close to the value presented by the lime powder (however lower, due to the presence of other compounds within the mortar mix). As mortar age progresses, the $\mathrm{pH}$ values decrease. At 90 days curing, all mortar samples present $\mathrm{pH}$ values close to the reference value for calcite. Specifically, L_M10.5 presents a $\mathrm{pH}$ value $\sim 3.9 \%$ higher than the reference calcite, the lime-metakaolin mortar with higher percentage metakaolin, L_M12.5, presents a $\mathrm{pH}$ value $\sim 1.4 \%$ lower than the reference calcite, the natural pozzolan present a $\mathrm{pH}$ value $\sim 7.4 \%$ lower than the reference calcite and the commercial lime-metakaolin mortar presents a $\mathrm{pH}$ value of about $1.4 \%$ percent lower than the reference calcite. Therefore, L_M10.5 is the only mortar presenting a $\mathrm{pH}$ value higher than the reference calcite, while the natural pozzolan mortar presents the highest difference in $\mathrm{pH}$ in relation to all samples, especially taking into account the fact that portlandite, which increases $\mathrm{pH}$ values, is still present within the aforementioned mortar. To conclude, in terms of $\mathrm{pH}$, the commercial lime-metakaolin mortar and L_M12.5 present the smallest difference with the reference calcite mortar at 90 days and a sorting of the mortars in this respect, in order of increasing difference in $\mathrm{pH}$ values with the reference calcite would be as follows: $L \_M 12.5 \sim M E<L \_M 10.5<L \_N P 12.5$.

To conclude, in terms of chemical compatibility with the calcareous stones, the following sorting can be made: $L \_M 12.5 \sim M E>L \_M 10.5>L \_N P 12.5$.

\subsection{Microstructural Compatibility}

In order to assess microstructural compatibility of the different restoration stones and the ancient stone the data of Table 3 was utilized. Three parameters were taken into account: porosity, bulk density and pore size distribution.

Regarding porosity, PAR_Sb presents the greatest similarity with the ancient stone, as it presents a porosity only $2 \%$ higher; PAR_Alb presents a porosity $\sim 10 \%$ higher than the ancient stone, while PAR_Sa presents a porosity 14\% lower than the ancient stone and PAR_K presents a porosity $~ 15 \%$ higher than the ancient stones. All quarry stones present values which are under $50 \%$ different than the porosity of the ancient stone and are thus assessed as compatible with the ancient stone, except for PAR_Dask, which presents a porosity value almost $88 \%$ lower than the ancient stone and is thus 
deemed incompatible in this sense (Table 18). Therefore, in terms of porosity, excluding PAR_Dask, the following sorting can be made: PAR_Sb $>P A R \_A l b>P A R \_S a>P A R \_K$.

Table 18. Relative difference of restoration stones' microstructural characteristics in relation to ancient stone samples.

\begin{tabular}{ccc}
\hline \multirow{2}{*}{ Restoration Stone } & \multicolumn{2}{c}{ Average Percentage Difference with Ancient Stone Samples } \\
\cline { 2 - 3 } & Porosity * & Bulk Density ** \\
\hline PAR_Sa & $-14.41 \%$ & $2.91 \%$ \\
PAR_Sb & $2.14 \%$ & $0.67 \%$ \\
PAR_Alb & $9.70 \%$ & $-2.01 \%$ \\
PAR_K & $15.15 \%$ & $-8.28 \%$ \\
PAR_Dask & $-87.59 \%$ & $15.88 \%$ \\
\hline
\end{tabular}

${ }^{*}\left(\mathrm{P}_{\mathrm{RS}}-\mathrm{P}_{\mathrm{ANCIENT}}\right)^{*} 100 / \mathrm{P}_{\mathrm{ANCIENT}}$, where $\mathrm{P}_{\mathrm{RS}}$ is the measured porosity of the quarry stone and $\mathrm{P}_{\mathrm{ANCIENT}}$ is the average value of porosities measured for the ancient stone samples. ${ }^{* *}\left(\mathrm{BD}_{\mathrm{RS}}-\mathrm{BD}_{\mathrm{ANCIENT}}\right)^{*} 100 / \mathrm{BD}_{\mathrm{ANCIENT}}$, where $\mathrm{BD}_{\mathrm{RS}}$ is the measured bulk density of the quarry stone and $\mathrm{BD}_{\mathrm{ANCIENT}}$ is the average value of bulk densities measured for the ancient stone samples.

Bulk density is also an important parameter, as it is related with the amount of required material for a restoration action, as well as with the loads which the monument will be burdened with after the application of the restoration material. Therefore, the use of a heavier stone will inflict higher static loads on the monument. In this sense, and aiming to a homogenous behavior of the structure as a whole, it is desired to select a restoration stone with the smallest difference of apparent density values in relation to the historical one. PAR_Sb presents the smallest difference, as its apparent density is less than $1 \%$ higher than the apparent density of the historical stones. PAR_Alb's apparent density is about $\sim 2 \%$ lower than that of the ancient stones, while PAR_Sa's is $\sim 3 \%$ higher than the value exhibited by the ancient stones. PAR_K presents a bulk density $\sim 8 \%$ lower than the ancient stones, while PAR_Dask is again deemed incompatible due to its much higher bulk density of $\sim 16 \%$ higher than the ancient stone. Therefore, excluding PAR_Dask, as it presents a difference in bulk density of $>10 \%$, a sorting from most appropriate to least appropriate material, would be: PAR_Sb $>$ PAR_Alb $>$ PAR_Sa $>$ PAR_K.

In addition to the similarity analysis between the microstructural characteristics, pore size distribution is, also crucial, as it is highly interconnected with mass transfer mechanisms, thus affecting material degradation mechanisms and moisture and salt accumulation in one material or the other. In the following table (Table 19) the relative percentage of pore volume per classes of pore sizes is presented for the ancient stone samples, which are the reference material, as well as the quarry stones. In the same table, the relation of pore volume corresponding to larger pores $(>0.1 \mu \mathrm{m})$ to the pore volume corresponding to smaller pores $(<0.1 \mu \mathrm{m})$ is also stated.

Table 19. Pore size distribution-Pore volume percentage corresponding to different pore size radii ranges.

\begin{tabular}{|c|c|c|c|c|c|c|}
\hline \multirow{2}{*}{ Sample } & \multicolumn{5}{|c|}{ Porosity Distribution (\%) per Different Pore Ranges } & \multirow{2}{*}{$\begin{array}{l}\text { Pore Volume }(<0.1 \mu \mathrm{m} \\
\text { Radii)/Pore Volume } \\
(>0.1 \mu \mathrm{m} \text { Radii })\end{array}$} \\
\hline & $\begin{array}{c}0.001-0.01 \\
\mu \mathrm{m}\end{array}$ & $\begin{array}{c}0.01-0.1 \\
\mu \mathrm{m}\end{array}$ & $0.1-1 \mu \mathrm{m}$ & $1-10 \mu \mathrm{m}$ & $>10 \mu \mathrm{m}$ & \\
\hline Ancient Stone 1 & 0.45 & 9.87 & 31.84 & 35.87 & 21.97 & 0.12 \\
\hline Ancient Stone 2 & 1.34 & 21.43 & 44.64 & 15.63 & 17.41 & 0.29 \\
\hline PAR_Sa & 2.61 & 20.11 & 20.18 & 13.43 & 43.67 & 0.29 \\
\hline PAR_Sb & 1.09 & 15.18 & 14.60 & 16.46 & 52.73 & 0.19 \\
\hline PAR_Alb & 1.20 & 8.50 & 17.07 & 16.77 & 56.41 & 0.11 \\
\hline PAR_K & 4.11 & 19.28 & 22.93 & 49.40 & 4.28 & 0.31 \\
\hline PAR_Dask & 0.53 & 33.33 & 56.61 & 6.88 & 3.17 & 0.51 \\
\hline
\end{tabular}

Ancient Stone sample 1, which seemed to be in a better state of preservation than Ancient Stone sample 2, presented a slightly different pore size distribution than Ancient Stone sample 2. Specifically, 
Ancient Stone 1 presented an equal accumulation of porosity in the ranges $0.1-1 \mu \mathrm{m}$ and $1-10 \mu \mathrm{m}$ $(\sim 32 \%$ and $\sim 36 \%$ respectively), while Ancient Stone 2 presented a shift towards lower pore radii (in the aforementioned ranges, $\sim 45 \%$ and $16 \%$ respectively). In order to facilitate comparison between the ancient stone samples and the quarry stones, the ratio of the sum of percentages of pore volume corresponding to pore radii below $0.1 \mu \mathrm{m}$ to the sum of percentages of pore volume corresponding to pore radii above $0.1 \mu \mathrm{m}$ was calculated for each lithotype. Compatibility requirements demand a similar ratio between the quarry stone and the ancient stone samples. All stone samples are within the range of the two ancient stone samples, except for PAR_Dask, which presents a much higher ration of small to large pores (marginally over the threshold value of 0.5), thus deeming it incompatible with the ancient stone. A sorting, showing the similarity in terms of pore size distribution between the ancient stones and the quarry stones, excluding PAR_K due to incompatibility, would be: PAR_Sb>PAR_Sa PAR_Alb> PAR_K.

Therefore, to conclude, the assessment of compatibility in terms of microstructural compatibility reveals that all quarry stones are within acceptable limits, except for PAR_Dask.

\subsection{Hygric Behavior of Ancient Stone, Quarry Stones and Mortars at 90 Days Curing-Compatibility and Performance}

In order to evaluate the combination of different types of material, a comparison of their hygric behavior through capillary rise test is essential. A homogenous hygric behavior of the structure as a whole is mandatory in order to achieve sustainability and avoid the accumulation of moisture in one material or the other. For the comparison, two values will be compared in relation to water uptake through capillary rise, the capillary rise coefficients (C.R.C), which correspond to the water uptake of each material through capillary rise and the water absorption capacity (WAC cap), which corresponds to the maximum amount of water uptake through capillary rise in relation to initial dry mass. Furthermore, water uptake capacity through total immersion $\left(\mathrm{WAC}_{\mathrm{imm}}\right)$ will also be taken into account (Table 20).

Table 20. Summary of hygric behavior parameters of stone samples and mortars.

\begin{tabular}{cccc}
\hline Sample & C.R.C. $\left(\mathbf{k g} /\left(\mathbf{m}^{\mathbf{2}} \mathbf{s}^{\mathbf{1} / \mathbf{2}}\right) \mathbf{)}\right.$ & WAC $_{\text {cap }} \mathbf{( \% )}$ & WAC $_{\mathbf{i m m}} \mathbf{( \% )}$ \\
\hline Ancient Stone 1 & N/A & N/A & 18.33 \\
Ancient Stone 2 & N/A & N/A & 9.01 \\
PAR_Sa & 0.013 & 5.18 & 6.06 \\
PAR_Sb & 0.366 & 8.96 & 9.96 \\
PAR_Alb & 0.349 & 8.00 & 9.46 \\
PAR_K & 0.015 & 6.97 & 7.09 \\
PAR_Dask & 0.005 & 1.46 & 1.31 \\
L_M10,5 & 0.203 & 21.47 & 22.62 \\
L_M12,5 & 0.206 & 21.48 & 23.08 \\
L_NP12,5 & 0.358 & 17.97 & 19.69 \\
ME & 0.065 & 14.85 & 15.48 \\
\hline
\end{tabular}

In relation to the capillary rise coefficients it is clear that the commercial restoration mortar presents a behavior similar to PAR_Sa, and PAR_K. The lime metaolin mortars present coefficients intermediate of the coefficients of the various quarry stones, while the lime-natural pozzolan mortar presents a capillary rise coefficient identical to PAR_Sb and PAR_Alb. Therefore, according to the quarry stone which will be used in the restoration, and taking into account that capillary rise measurements are not possible to conduct on the ancient stone, different mortars are deemed as appropriate. Regarding the water absorption capacity through capillary rise, it is obvious that all mortars present higher values than the quarry stones; this is expected, as mortars, containing a larger amount of binding material, absorb more water through capillarity than stones. It should be noted that the lime-natural pozzolan mortar and the commercial lime-metakaolin mortar present the closest values to the stone in this respect 
than all other mortar mixes. Therefore, the use of PAR_Sa and PAR_K as restoration stones would promote the selection of the commercial lime-metakaolin mortar, ME, the use of PAR_Alb and PAR_Sb would promote the selection of the lime-natural pozzolan mortar, L_NP12.5, while the lime-metakaolin mortars, L_M10.5 and L_M12.5 could be used with all quarry stones in an adequate manner.

The water absorption capacity through total immersion is extremely important in this assessment, as measurements were conducted on the ancient samples as well. It is noted that, as aforementioned, the Italian restoration stone will be removed from the monument and is thus not included in the comparison. All quarry stones present lower values than the ancient stones, however within an acceptable range, except for PAR_Dask, which presents a much lower value and is deemed incompatible. The restoration mortars present higher values, however, within an acceptable range, with the lime-natural pozzolan mortar and the commercial lime-metakaolin mortar presenting the most similar values to the ancient stone samples and the quarry stones.

\subsection{Mechanical Behavior Assessment_Compatibility and Performance}

On a first level of evaluating the compressive strength values of the quarry stones and the ancient stone (Table 6), it is important that the new stone presents mechanical strength values similar to the historical material in order to ensure that the historical material is preserved in the case of an earthquake; if the historical material presents much lower mechanical strength values it is probable that it will be subjected to damage, leaving the new material intact. On a second level of assessment, low anisotropy is demanded from the repair material, in order not to contribute to the overall anisotropic behavior of the structure, which leads to failures due to differential stresses. This can be assessed by comparing the mean with the characteristic compressive strength value, where large discrepancies are not desired and are a reason for excluding a stone type from the final selection. On a third level of assessment, adequate compressive strength is desired in order to ensure the mechanical performance of the structure as a whole. In the following table (Table 21), the average compressive strength of each quarry stone is compared with the ancient stone average compressive strength (CS), while the characteristic compressive strength of each quarry stone is also compared with the same value.

Relative difference (\%) in relation to ancient stone: $\left(\mathrm{CS}_{\text {quarry }}-\mathrm{CS}_{\text {ancient }}\right)^{*} 100 / \mathrm{CS}_{\text {ancient }}$

Table 21. Difference (\%) of quarry stones in relation to ancient stone in terms of compressive strength.

\begin{tabular}{ccc}
\hline \multirow{2}{*}{ Quarry Stone } & \multicolumn{2}{c}{ Relative Difference with Ancient Stone (\%) } \\
\cline { 2 - 3 } & Using Average Compressive Strength & Using Characteristic Compressive Strength \\
\hline PAR_Sa & 45 & -16 \\
PAR_Sb & 152 & -73 \\
PAR_Alb & -10 & -32 \\
PAR_K & 62 & 44 \\
PAR_Dask & 1001 & 775 \\
\hline & $\left(\mathrm{CS}_{\text {quarry }}-\mathrm{CS}_{\text {ancient }}\right)^{*} 100 / \mathrm{CS}_{\text {ancient, }}$ where $\mathrm{CS}$ is measured compressive strength.
\end{tabular}

The stone from the quarry in Spain, PAR_Alb, is the only lithotype which presents a mean compressive strength value lower than the historical one (10\% lower), while when using the characteristic compressive strength, it presents $32 \%$ lower values. The stone from Location A of the Rhodes quarry (PAR_Sa) and the stone from Cyprus present an average compressive strength of $45 \%$ and $62 \%$ higher than the historical stone, respectively, values which exceed the estimated compressive strength of the historical stones within an acceptable (or even desired in terms of performance) range. These values are even more acceptable in terms of compatibility when the characteristic compressive strength of each stone is utilized, without greatly jeopardizing performance. The stone from Location B in Rhodes (PAR_Sb) and the stone from the Achaia quarry, present average mechanical strength values 
greatly exceeding the historical stone's compressive strength; in particular, the Rhodes stone (PAR_Sb) presents compressive strength values exceeding the historical stone by $152 \%$, while the Achaia stone (PAR_Dask) presents values 1001\% higher than the historical stone. Furthermore, when taking into account the characteristic compressive strength, PAR_Sb presents the exact opposite problem, as it presents a by $73 \%$ lower compressive strength value, thus jeopardizing the mechanical performance of the structure, which would be greatly diminished by its use, while PAR_Dask still presents an extremely high relative difference with the ancient stone of $775 \%$.

Comparing average compressive strength and characteristic compressive strength of each stone type also provides useful results. The stone from the one Rhodes quarry (PAR_Sa) presents a characteristic compressive strength value $42.2 \%$ lower than the average compressive strength value, while the stone from the other Rhodes quarry presents a characteristic compressive strength value almost $90 \%$ lower than the average value. This is an indication of high anisotropy regarding mechanical strength values in the second stone and deems it inappropriate for use in the upcoming restoration project. The stone from the quarry in Spain present a characteristic compressive strength value $\sim 25 \%$ lower than the average value, however this type of stone presents low mechanical strength values and is not strong enough to be effective in the upcoming restoration project. The stone from Cyprus presented the smallest difference between average and characteristic compressive strength (the latter being $\sim 11 \%$ lower than the former). The stone from Achaia presented a characteristic compressive strength value of $\sim 20 \%$ lower than its average compressive strength, which is an intermediate decrease in the present study; however, as mentioned above, this lithotype is considered inappropriate, due to extremely high compressive strength.

Therefore, in terms of compatibility, PAR_Dask is deemed as highly incompatible, while in terms of mechanical performance PAR_Sb is deemed as inadequate to provide the required level of mechanical performance and as a risk due to its high inhomogeneity and anisotropy. Amongst the other quarry stones, PAR_Alb and PAR_Sa are within acceptability limits in relation to compatibility; however, PAR_Alb, may not be able to provide the required level of mechanical performance, as it is weaker than the ancient stone. PAR_K is marginally too strong to be assessed as compatible, as it presents compressive strength values over $50 \%$ higher than the ancient stone; however, this is true only when taking into account the average compressive strength (62\% stronger), while when taking into account the characteristic compressive strength the same relative difference is $44 \%$.

The designed mortars are all deemed as compatible with the ancient stone in terms of compatibility regarding mechanical strength, as they all present compressive strength values lower or equal to the ancient stone and the various quarry stones (Tables 6 and 15), therefore mechanical performance can play the decisive role. Therefore, the commercial lime-metakaolin mortars ME is considered as the most appropriate in this sense, followed by the two lime-metakaolin mortars. The lime-pozzolan mortar presented too low values of compressive and flexural strength and will not be able to provide an acceptable level of performance. Therefore, in terms of performance the lime-pozzolan mortar must be excluded from the selection process. Comparing the ultrasound velocities of the mortars with the ultrasound measurements of the quarry stones, it is obvious that all designed mortars present values ( $\sim 2000 \mathrm{~m} / \mathrm{s}$, Table 16) intermediate the different quarry stones (1000-3000 m/s, Table 7), of course with the exception of PAR_Dask, which presents excessively high values.

\subsection{Aesthetic Compatibility in Terms of Color}

The stone used for the restoration must present a similar appearance of color with the ancient stone; a small difference is desired, however only slightly discerned by the human eye. The restoration mortar must also present a similar appearance, also only slightly discerned by the human eye, as this is not a masonry, but a stone monument where mortars are to be used to join together fragmented members and ancient and restoration members for each drum and must be discretely applied. In order to compare the different materials, as explained in Section 3.1.9 and Section 3.2.8, it was decided to compare two parameters: the difference in saturation $\Delta \mathrm{C}^{*} 1,2$ and the difference in hue $\left(\Delta \mathrm{H}^{*} 2,1\right)$, the 
quarry stones in relation to the ancient stone, and the pigmented restoration mortars in relation to both the ancient stone and separately each quarry stone.

PAR_K and PAR_Sb presented the lowest differences in chroma and hue in relation to the ancient stone sample, followed by PAR_Sa (Table 8). PAR_Alb presented a higher difference in relation to the two selected parameters, however within acceptable limits, while PAR_Daskpresented the highest difference in color and hue. Therefore, a sorting in terms of aesthetic compatibility with the ancient stone, would be as follows: PAR_K PAR_Sb $>$ PAR_Sa $>$ PAR_Alb $>$ PAR_Dask.

In relation to the mortars, the addition of burnt obra ( $0.5 \%$ in relation to dry mortar) and ochre $(0.25 \%$ in relation to dry mortar) presented the lowest chroma and hue difference with the ancient stone (Table 17). Through the addition of the aforementioned pigment combination, the mortar presents the highest compatibility regarding difference in hue and chroma, not only in relation to the ancient stone, but also to all lithotypes (Table 22), except for PAR_Dask, which is in any case incompatible in terms of color with the ancient stone, and PAR_Sa, where the addition of $0.75 \%$ sienna and the addition of $0.5 \%$ burnt obra; $0.25 \%$ sienna presented higher compatibility in terms of color, followed by the mortar with the addition of $0.5 \%$ burnt obra; $0.25 \%$ ochre.

Table 22. Assessment of pigmented restoration mortar in relation to different quarry stones in terms of color.

\begin{tabular}{|c|c|c|c|c|c|c|c|c|c|c|}
\hline \multirow{3}{*}{$\begin{array}{c}\text { Pigmented } \\
\text { Restoration Mortar }\end{array}$} & \multicolumn{10}{|c|}{ In Relation to } \\
\hline & \multicolumn{2}{|c|}{ PAR_Sa } & \multicolumn{2}{|c|}{ PAR_Sb } & \multicolumn{2}{|c|}{ PAR_Alb } & \multicolumn{2}{|c|}{ PAR_K } & \multicolumn{2}{|c|}{ PAR_Dask } \\
\hline & $\Delta C_{2,1}^{*}$ & $\Delta H^{*}{ }_{2,1}$ & $\Delta C_{2,1}^{*}$ & $\Delta H_{2,1}^{*}$ & $\Delta C_{2,1}^{*}$ & $\Delta H_{2,1}^{*}$ & $\Delta C^{*} 2,1$ & $\Delta H_{2,1}^{*}$ & $\Delta C_{2,1}^{*}$ & $\Delta H^{*}{ }_{2,1}$ \\
\hline without pigment & -6.44 & 1.10 & -9.64 & 1.98 & -14.33 & 1.45 & -11.28 & 1.13 & -7.63 & 1.11 \\
\hline $0.75 \%$ cassia & 9.12 & 2.30 & 5.92 & 1.08 & 1.23 & 3.02 & 4.28 & 3.18 & 7.93 & 2.53 \\
\hline $0.75 \%$ burnt obra & -0.05 & 2.55 & -3.24 & 1.77 & -7.93 & 3.34 & -4.89 & 3.37 & -1.23 & 2.77 \\
\hline $0.75 \%$ sienna & 0.86 & 0.37 & -2.34 & 1.60 & -7.03 & 0.48 & -3.98 & 0.12 & -0.33 & 0.30 \\
\hline $0.75 \%$ ochre & 21.84 & 0.28 & 18.65 & 1.64 & 13.96 & 0.37 & 17.00 & 0.88 & 20.66 & 0.44 \\
\hline $0.75 \%$ burnt sienna & 1.73 & 3.94 & -1.46 & 3.28 & -6.15 & 5.18 & -3.11 & 5.07 & 0.55 & 4.24 \\
\hline $0.75 \%$ obra & -4.69 & 1.44 & -7.89 & 2.49 & -12.58 & 1.89 & -9.53 & 1.49 & -5.87 & 1.45 \\
\hline $\begin{array}{c}0.5 \% \text { burnt obra; } \\
0.25 \% \text { ochre }\end{array}$ & 5.79 & 1.07 & 2.59 & 0.18 & -2.10 & 1.41 & 0.95 & 1.68 & 4.60 & 1.24 \\
\hline $\begin{array}{c}0.5 \% \text { burnt obra; } \\
0.25 \% \text { sienna }\end{array}$ & 0.10 & 1.97 & -3.10 & 1.10 & -7.79 & 2.58 & -4.74 & 2.67 & -1.09 & 2.15 \\
\hline
\end{tabular}

\section{Conclusions}

It is evident from the above study results, that the comparison of quarry stones with historical materials is a multi-layered issue. When selecting a new stone for the restoration of a stone monument, many characteristics must be taken into account, as the new stone will become part of the structure. The restored structure must behave in a homogenous manner, both in regard to moisture transfer phenomena, as well as in regard to mechanical behavior. The historical stone of the monument has undergone weathering, which has altered its characteristics; this must be taken into account. However, the characteristics of the weathered stone are the characteristics which must be taken into account when assessing the compatibility of the new stone. Other considerations must also be taken into account; monuments hold historical and artistic significance, and the new stone must complement these values. Therefore, it is desirable to select a stone of similar petrographic and mineralogical characteristics, in order to be consistent with the historical material. Furthermore, it is important that the restored monument have a homogenous appearance; the new stone additions must be discernable, in order to enhance the historic value of the structure, and in accordance to the Charters regarding restoration actions, however aesthetic compatibility must be achieved. From the results of the current study, it is deducted that color difference $(\Delta \mathrm{E})$ alone is not indicative, as differences in surface texture can lead to misleading results. On the contrary, when comparing different materials in relation to their color characteristics, difference in saturation and in hue may sometimes provide more representative results and visual observations must never be forsaken. Therefore, it is evident that a 
number of complementary techniques must be applied in order to assess all aspects of compatibility and performance, as each technique provides different information.

The ancient stone of the Temple of Apollo Pythios is a biocalcarenite, with a high calcite content. Amongst the five quarry stones examined in terms of compatibility, it is evident that the stone from the Achaia quarry, PAR_Dask is highly incompatible with the ancient stone, as it presents not only different petrographic and mineralogical characteristics, but also a different chemical composition, a much denser microstructure, a completely different behavior to water uptake through capillary rise, much higher mechanical strength. This is indicative that the use of the Achaia stone for the restoration of the Temple would create problems on different levels; humidity would be accumulated in the ancient material and in the case of a dynamic stress, such as an earthquake, stresses would be accumulated on the weaker ancient material, which would fracture preferentially. The Achaia stone is also aesthetically incompatible, as evidenced through its difference in saturation and hue with the ancient stone. The other stones present characteristics closer to the ancient stone and present a higher level of compatibility. The stone from Location B of the Rhodes quarry and the stone from Spain present a much higher average pore radius than the ancient stone, as well as the highest values of capillary rise coefficients and absorbed water. This is an indication, that their use could increase total moisture uptake of the structure. Additionally, the stone from the quarry in Spain does not present an adequate level of mechanical strength, as its compressive strength is lower than the ancient stone and its use would not infer the desirable level of performance, while the stone from Location B of the Rhodes quarry presents a great difference between average and characteristic mechanical strength values, indicating high anisotropy of the material, which is undesirable. Lithotypes from Location A of the Rhodes quarry (which is, as noted, at this point inactive) and from the Cyprus quarry, apart from presenting the most appropriate characteristics in relation to the above considerations, also present the smallest differences in saturation and color, however, due to their particular microstructure and taking into account the harsh environmental factors of the monument, salt crystallization ageing tests are necessary before proceeding to the selection of any of the examined lithotypes.

Regarding the restoration mortars examined, all examined mortars present an acceptable level of compatibility; however, a selection should be made after concluding which lithotype will be used for the restoration - the restoration mortar must present compatibility with both the ancient stone and the new stone. However, it should be noted that the lime-natural pozzolan mortar does not present an adequate level of mechanical strength at 90 days; furthermore, the $\mathrm{pH}$ value is still higher than the threshold level at 90 days. The lime-metakaolin mortars and the commercial lime-metakaolin mortar succeed in the early acquisition of adequate mechanical strength values, as well as in the early consumption of portlandite. The use of the commercial lime-metakaolin restoration mortar would be preferable, due to its faster consumption of portlandite and higher mechanical strength values and thus its beneficial effect on the structure's mechanical performance; however, the selection of the optimum restoration mortar is dependent on the lithotype which will be selected for the restoration. The use of pigments in the restoration mortar showed that the combination of burnt obra and ochre in small percentages to the total dry mortar can achieve the desired effect, achieving compatibility in terms of color with both the ancient stone and the quarry stones.

Through this study, the importance of diagnosis and historical materials' characterization is highlighted as the basis for the design and assessment of restoration materials and interventions. The selection of proper materials, that fulfill compatibility and performance requirements, is necessary in order to ensure the sustainable preservation of monuments.

Author Contributions: M.A. conducted the writing and editing of the paper, supervised the investigation related to restoration mortars and implemented the investigation related to thermal analysis investigations; V.K. implemented measurements concerning the historical materials and supervised the investigation related to restoration stones; N.G. implemented the investigation related to the quarry stones; M.K. (Myrto Kalofonou) implemented the investigation connected to the restoration mortars; C.S. implemented the investigation connected to the pigmented restoration mortars; M.K. (Maria Karoglou) supervised the investigations related to the historical materials, offered the methodology related to hygric behavior measurements and supervised the 
related measurements; E.T.D. offered the methodology concerning material characterization and supervised petrographic and mineralogical examination measurements, as well as the aesthetical compatibility related investigation; C.M. implemented the investigation of the quarry stone's mechanical properties; A.B. implemented the investigation related to the materials' microstructure; A.M. was responsible for the funding acquisition, project governance, scientific supervision of the NTUA team and all related measurements and data curation, supervision of the overall writing of the paper, offered the overall methodology and visualization and designed all aspects of the project and research conducted; M.P. and A.K. offered documentation data related to the monument and its materials and assisted in material provision and sampling; E.F. and M.M. offered important information regarding archaeological and historical data related to the monument; M.M. also set the requirements for research, with the contribution of M.P., A.K. and E.F. All authors contributed to the writing of the paper in their respective areas of investigation.

Funding: “This research was assigned to NTUA by the Ministry of Culture and Sports of the Hellenic Republic, Ephorate of Antiquities of Dodecanese and was funded by the NSRF 2014-2020 grant number 910004". There is no APC funding.

Acknowledgments: This research was conducted within the framework of the research program regarding the "Diagnostic study of the current state of the Temple of Apollo Pythios in the Ancient Acropolis of Rhodes and examination of proposals regarding conservation and restoration materials and techniques", that was assigned to NTUA by the Ministry of Culture and Sports of the Hellenic Republic. The authors would like to acknowledge the Ministry of Culture and Sports for their cooperation on the Research Project for Apollo Pythios Temple that has made this publication possible. The authors would like to thank the employees of the Ephorate of Antiquities of Dodecanese for their valuable information, insights and for the fruitful cooperation during the different stages of the study and especially the archeologists and engineers who are co-authors of this paper and who played a functional role in this study, through the collection and documentation of data, as well as the design of the study. The authors would like to acknowledge TITAN S.A. for their cooperation in issues related to restoration mortars, and the Institute of Geology and Mineral Exploration of Greece for their valuable contribution in the petrographic examination of the stone samples. The authors would like to thank NTUA Prof. Charalampos Ioannidis, from the School of Rural and Surveying Engineering and NTUA Prof. Ioannis Psicharis, from the School of Civil Engineering, for the interdisciplinary cooperation regarding the study of the monument. This research was presented in its initial form at the 1st International Conference TMM_CH: Transdisciplinary Multispectral Modelling and Cooperation for the Preservation of Cultural Heritage, held on 10-13 October 2018 at the Eugenides Foundation Athens, Greece under the title "A study regarding the historical materials of the Apollo Pythios Temple in Rhodes for the design and selection of appropriate restoration materials" and has since then been elaborated with further results and interpretations.

Conflicts of Interest: The authors declare no conflicts of interest. Archaeologist and engineer employees of the Greek Ministry of Culture, Ephorate of Antiquities of Dodecanese, who are co-authors in this study, have played a functional role relating to the historical and archaeological aspects of the monument, as well as setting requirements for research.

\section{References and Notes}

1. Pitilakis, K.; Tavouktsi, E. Seismic response of the columns of two ancient Greek temples in Rhodes and Lindos. In Proceedings of the 8th International Symposium on the Conservation of Monuments in the Mediterranean Basin, Patra, Greece, 31 May-2 June 2010; Volume 31.

2. Maravelaki-Kalaitzaki, P. Black crusts and patinas on Pentelic marble from the Parthenon and Erechtheum (Acropolis, Athens): Characterization and origin. Anal. Chim. Acta 2005, 532, 187-198. [CrossRef]

3. Craig, H.; Craig, V. Greek Marbles: Determination of Provenance by Isotopic Analysis. Science 1972, 176, 401-403. [CrossRef] [PubMed]

4. Korres, E. From Pentelicon to the Parthenon; Melissa Publications: Athens, Greece, 2001.

5. Malacrino, C.G. Constructing the Ancient World: Architectural Techniques of the Greeks and Romans; Getty Publications: Los Angeles, CA, USA, 2010.

6. Moropoulou, A.; Bakolas, A.; Moundoulas, P.; Aggelakopoulou, E. Reverse engineering: A proper methodology for compatible restoration mortars. In Proceedings of the Workshop Repair Mortars for Historic Masonry, TC RMH, Delft, The Netherlands, 25-28 January 2005; pp. 25-28.

7. Grammatikakis, G.; Demadis, K.D.; Melessanaki, K.; Pouli, P. Laser-assisted removal of dark cement crusts from mineral gypsum (selenite) architectural elements of peripheral monuments at Knossos. Stud. Conserv. 2015, 60 (Suppl. 1), S3-S11. [CrossRef]

8. Avdelidis, N.P.; Moropoulou, A.; Theoulakis, P. Detection of water deposits and movement in porous materials by infrared imaging. Infrared Phys. Technol. 2003, 44, 183-190. [CrossRef] 
9. Moropoulou, A.; Bakolas, A.; Bisbikou, K. Investigation of the technology of historic mortars. J. Cult. Herit. 2000, 1, 45-58. [CrossRef]

10. Moropoulou, A.; Labropoulos, K.C.; Delegou, E.T.; Karoglou, M.; Bakolas, A. Non-Destructive Techniques as a tool for the protection of Built Cultural Heritage. Constr. Build. Mater. 2013, 48, 1222-1239. [CrossRef]

11. Moropoulou, A. Reverse engineering to discover traditional technologies: A proper approach for compatible restoration mortars. In Proceedings of the International RILEM Workshop on Repair Mortars for Historic Masonry, Delft, The Netherlands, 26-28 January 2005 ; pp. 278-291.

12. Moropoulou, A.; Haralampopoulos, G.; Tsiourva, T.; Auger, F.; Birginie, J.M. Artificial weathering and non-destructive tests for the performance evaluation of consolidation materials applied on porous stones. Mater. Struct. 2003, 36, 210-217. [CrossRef]

13. Moropoulou, A.; Koui, M.; Kourtlei, C.; Theoulakis, P.; Avdelidis, N.P. Integrated methodology for measuring and monitoring salt decay in the medieval city. Mediterr. Archaeol. Archaeom. 2001, 1, 57-68.

14. Apostolopoulou, M.; Aggelakopoulou, E.; Bakolas, A.; Moropoulou, A. Compatible Mortars for the Sustainable Conservation of Stone in Masonries. In Advanced Materials for the Conservation of Stone; Hosseini, M., Karapanagiotis, I., Eds.; Springer: Cham, Switzerland, 2018; pp. 97-123.

15. Rodrigues, J.D.; Grossi, A. Indicators and ratings for the compatibility assessment of conservation actions. J. Cult. Herit. 2007, 8, 32-43. [CrossRef]

16. Adamopoulos, E.; Tsilimantou, E.; Keramidas, V.; Apostolopoulou, M.; Karoglou, M.; Tapinaki, S.; Ioannidis, C.; Georgopoulos, A.; Moropoulou, A. Multi-sensor doc-umentation of metric and qualitative information of historic stone structures. ISPRS Ann. Photogramm. Remote Sens. Spat. Inf. Sci. 2017, 4, 1-8.

17. Laurenzi, L. I monumenti dell' antica Rodi. In Memorie dell' Istituto storico-arceologico FERT, vol. II, 1938, s.25-29.

18. Fain, E. Comportamento e durabilita delle "stutturemiste" in area archeologica. Il tempio di Apollo Pizio all' Acropoli di Rodi. Politecnico di Milano. Ph.D. Thesis, Politecnico di Milano, Milan, Italy, 2015.

19. Soile, S.; Tsilimantou, E.; Keramidas, V.; Karoglou, M.; Bourexis, F.; Adamopoulos, E.; Delegou, E.T.; Lampropoulos, K.; Ioannidis, Ch.; Moropoulou, A.; Pikoula, M.; Farmakidou, E.; Michailidou, M. Multidisciplinary Documentation: Combination of NDTs with geometric documentation for the diagnostic study of Ancient Temples - The case of the Pythian Apollo Temple in Rhodes, in Nondestructive Evaluation and Monitoring Technologies, Documentation, Diagnosis and Preservation of Cultural Heritage, Editors Ahmad Osman and Antonia Moropoulou, pp 18, 2019 (accepted).

20. Moropoulou, A.; Avdelidis, N.P.; Karoglou, M.; Delegou, E.T.; Alexakis, E.; Keramidas, V. Multispectral applications of infrared thermography in the diagnosis and protection of built cultural heritage. Appl. Sci. 2018, 8, 284. [CrossRef]

21. Normal 27/88: Caratterizzazione di unamalta Roma CNR ICR; Consiglio Nazionale delle Ricerche and Istituto Centrale del Restauro (CNR-ICR): Rome, Italy, 1988.

22. Moropoulou, A.; Bakolas, A.; Bisbikou, K. Characterization of ancient, byzantine and later historic mortars by thermal analysis and X-ray diffraction techniques. Thermochim. Acta 1995, 269, 779-795. [CrossRef]

23. Normal 34/91: Analysis of Clay Materials by XRD Rome; Consiglio Nazionale delle Ricerche and Istituto Centrale del Restauro (CNR-ICR): Rome, Italy, 1991.

24. Normal 4/80: Distribution of Pore Volume as a Function of Pore Diameter C.N.R.-I.C.R; Consiglio Nazionale delle Ricerche and Istituto Centrale del Restauro (CNR-ICR): Rome, Italy, 1980.

25. EN15801: 2010: Conservation of Cultural Property-Test Methods-Determination of Water Absorption by Capillarity; European Commitee for Standardisation: Brussels, Belgium, 2010.

26. EN 1926:1999: Natural Stone Test Methods-Determination of Compressive Strength; European Committee for Standardisation: Brussels, Belgium, 1999.

27. EN 1015-11:2007: Methods of Test for Mortar for Masonry_Part 11. Determination of Flexural and Compressive Strength of Hardened Mortars; European Commitee for Standardisation: Brussels, Belgium, 2007.

28. EN15886:2010: Conservation of Cultural Property-Test Methods-Colour Measurement of Surfaces; European Commitee for Standardisation: Brussels, Belgium, 2010.

29. EN1015-3:2007: Methods of Test for Mortar for Masonry_Part 3. Determination of Consistence of Fresh Mortar (by Flow Table); European Commitee for Standardisation: Brussels, Belgium, 2007.

30. EN1015-6:2007: Methods of Test for Mortar for Masonry — Part 6: Determination of Bulk Density of Fresh Mortar; European Commitee for Standardisation: Brussels, Belgium, 2007. 
31. EN1015-8:2007: Methods of Test for Mortar for Masonry_Part 8. Determination of Retained Water of Fresh Mortar; European Commitee for Standardisation: Brussels, Belgium, 2007.

32. Aggelakopoulou, E.; Bakolas, A.; Moropoulou, A. Properties of lime-metakaolin mortars for the restoration of historic masonries. Appl. Clay Sci. 2011, 53, 15-19. [CrossRef]

33. Vejmelková, E.; Keppert, M.; Keršner, Z.; Rovnaníková, P.; Černý, R. Mechanical, fracture-mechanical, hydric, thermal, and durability properties of lime-metakaolin plasters for renovation of historical buildings. Constr. Build. Mater. 2012, 31, 22-28. [CrossRef]

34. Gameiro, A.; Santos Silva, A.; Faria, P.; Grilo, J.; Branco, T.; Veiga, R.; Velosa, A. Physical and chemical assessment of lime-metakaolin mortars: Influence of binder:aggregate ratio. Cem. Concr. Compos. 2014, 45, 264-271. [CrossRef]

35. Moropoulou, A.; Bakolas, A.; Anagnostopoulou, S. Composite materials in ancient structures. Cem. Concr. Compos. 2005, 27, 295-300. [CrossRef]

36. Normal 13/83: Dosage of Soluble Salts Rome; Consiglio Nazionale delle Ricerche and Istituto Centrale del Restauro (CNR-ICR): Rome, Italy, 1983.

(C) 2019 by the authors. Licensee MDPI, Basel, Switzerland. This article is an open access article distributed under the terms and conditions of the Creative Commons Attribution (CC BY) license (http:/ / creativecommons.org/licenses/by/4.0/). 